Supporting Information for

\title{
Sulfonic Acid and Ionic Liquid Functionalized Covalent Organic Framework for Efficient Catalysis of the Biginelli Reaction
}

Bing-Jian Yao, ${ }^{\ddagger}$ Wen-Xiu Wu, ${ }^{\ddagger}$ Luo-Gang Ding, Yu-Bin Dong*

College of Chemistry, Chemical Engineering and Materials Science, Collaborative Innovation Center of Functionalized Probes for Chemical Imaging in Universities of Shandong, Key Laboratory of Molecular and Nano Probes, Ministry of Education, Shandong Normal University, Jinan 250014, P. R. China.

Email: yubindong@sdnu.edu.cn

${ }^{\ddagger}$ These authors contributed equally.

The Table of Contents Entry

1. Characterization of Model Compounds $\quad$ S2

2. Characterization of COF-IM and COF-IM- $\mathrm{SO}_{3} \mathrm{H}$

3. Catalytic Biginelli Reaction over $\mathrm{COF}-\mathrm{IM}-\mathrm{SO}_{3} \mathrm{H} \quad$ S9

4. Characterization of the Biginelli Reaction products over COF-IM- $\mathrm{SO}_{3} \mathrm{H}$ (for Table 1) S12

5. Proposed Mechanism S33

6. Scaled-up Model Biginelli Reaction $\quad$ S34 


\section{Characterization of Model Compounds}

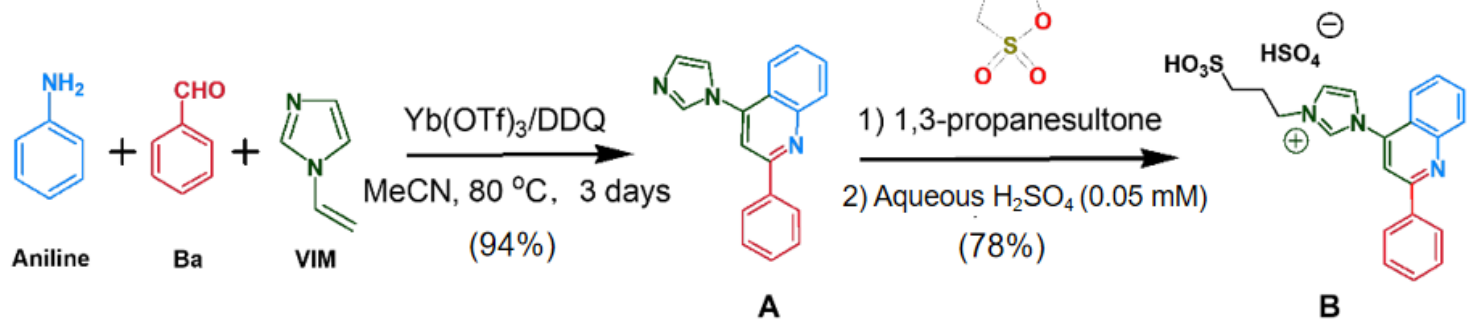

Scheme S1 Synthesis of model compounds A and B.

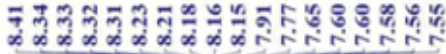

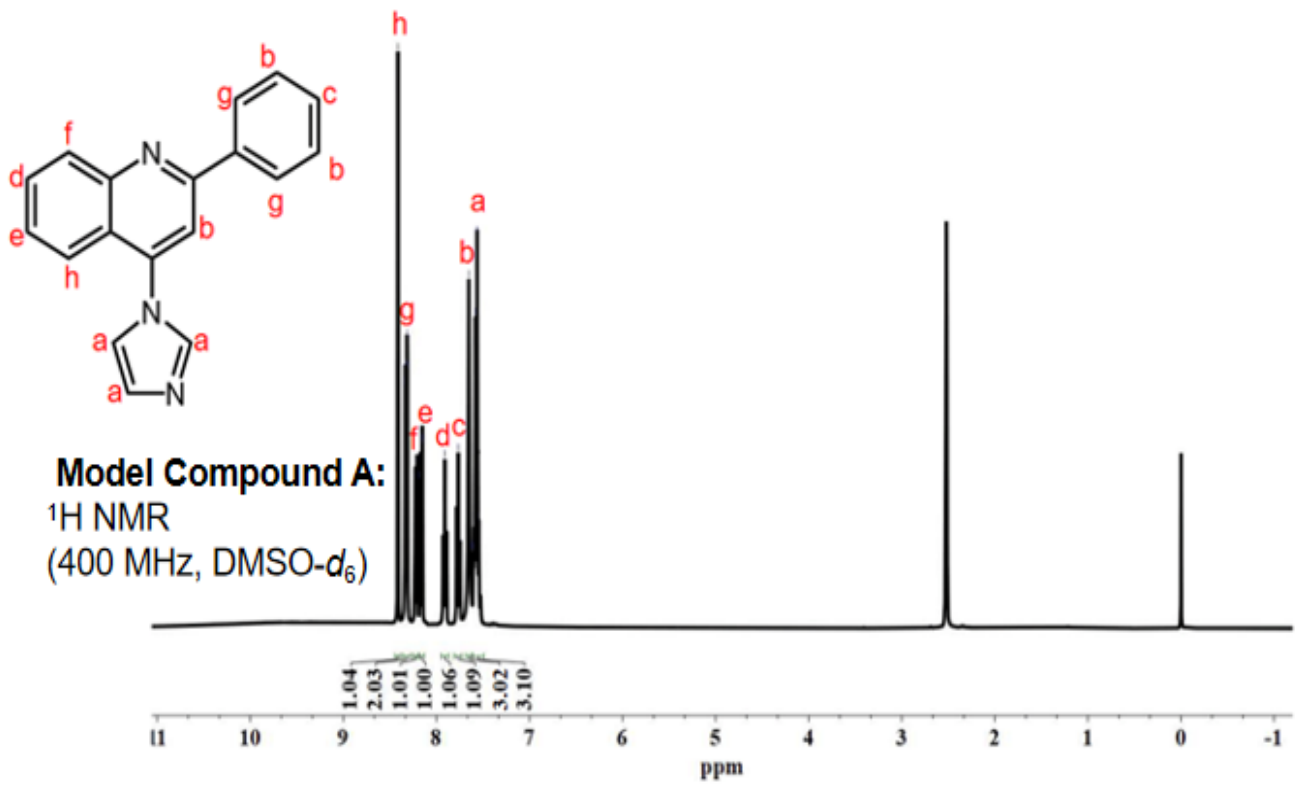




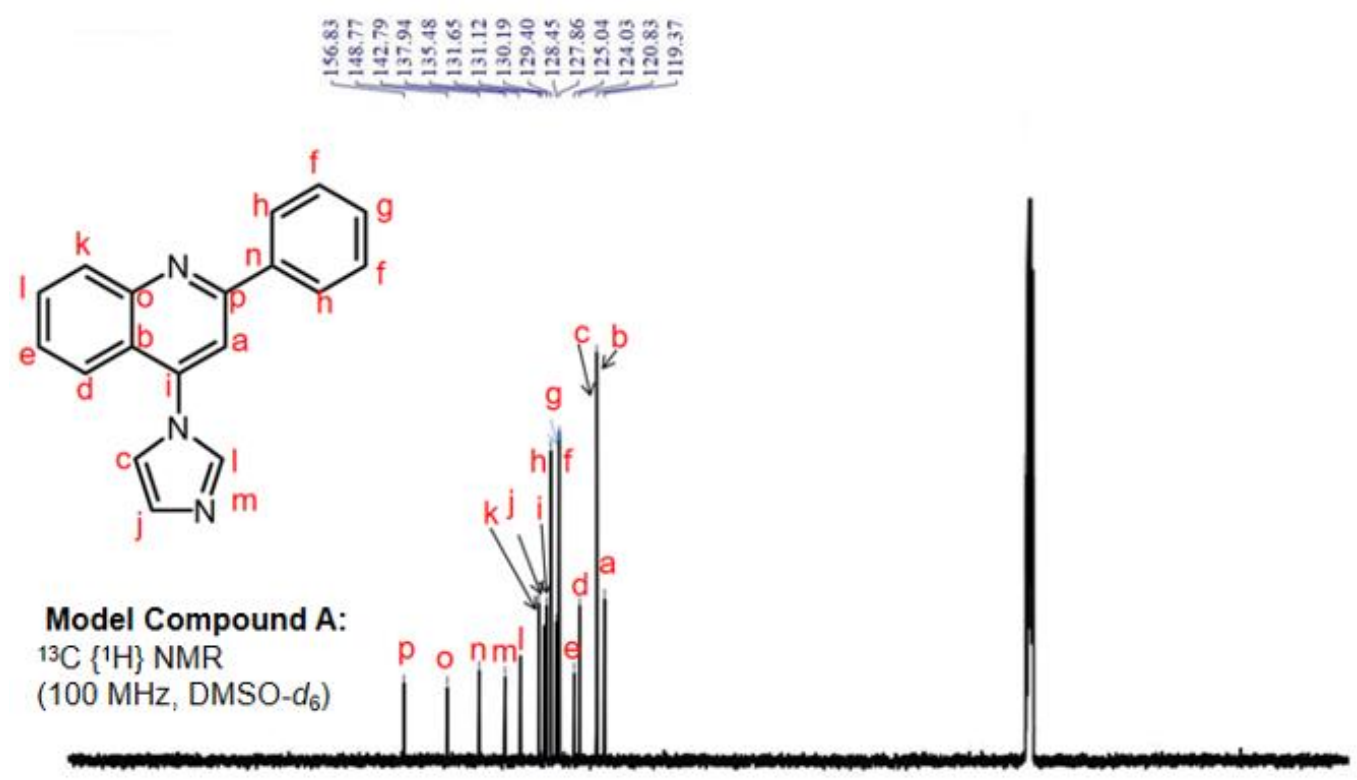

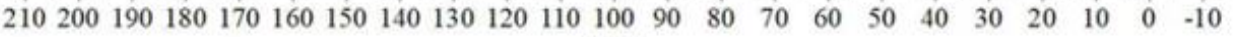
$\mathrm{ppm}$

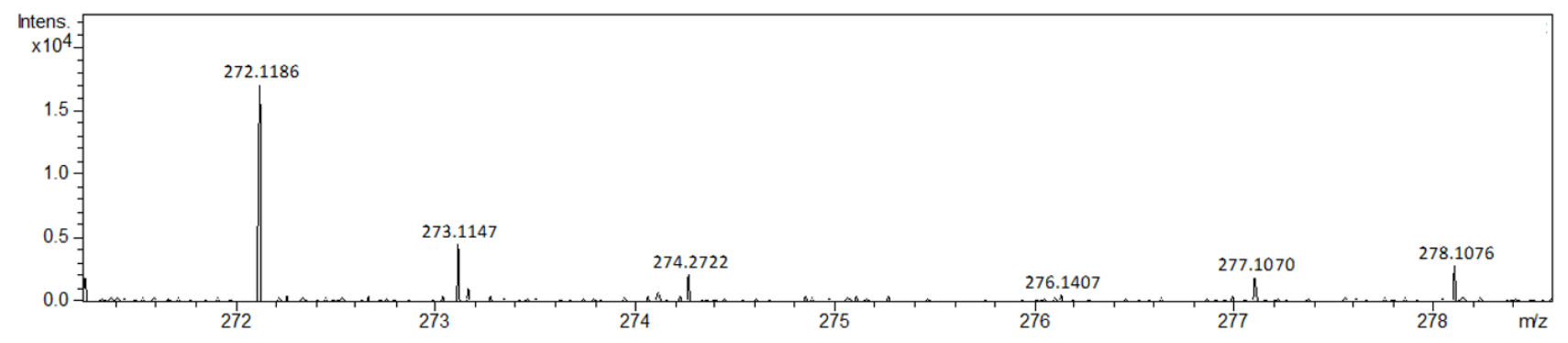

Figure S1. ${ }^{1} \mathrm{H}$ NMR, ${ }^{13} \mathrm{C}$ NMR and MS spectra of model compound $\mathbf{A}$.

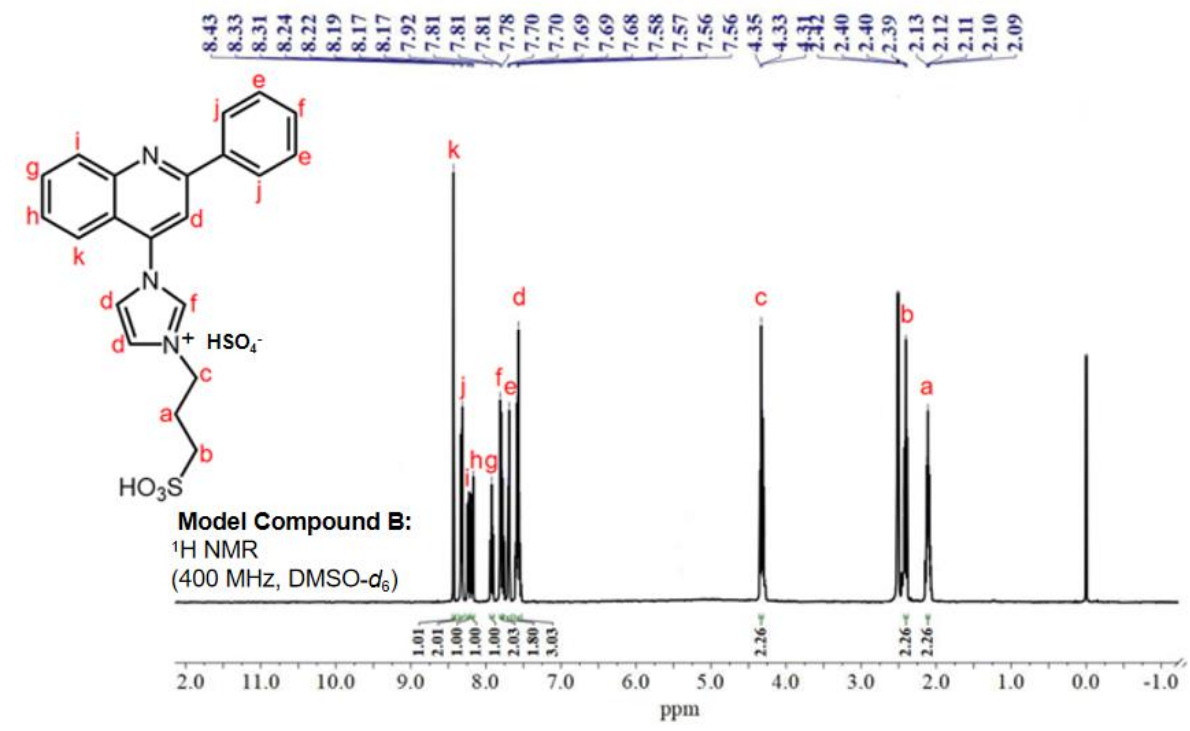



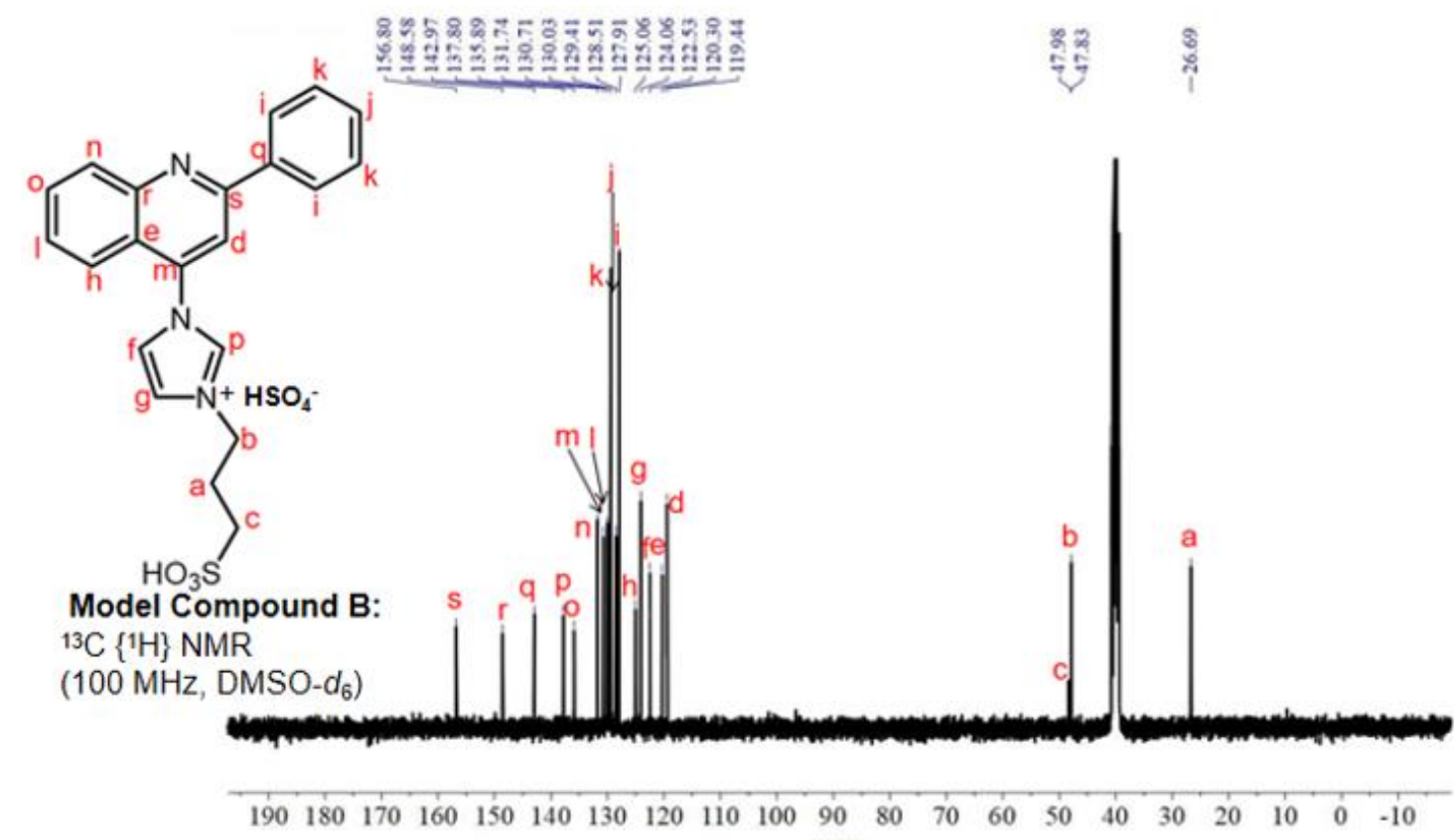
ppm

a)

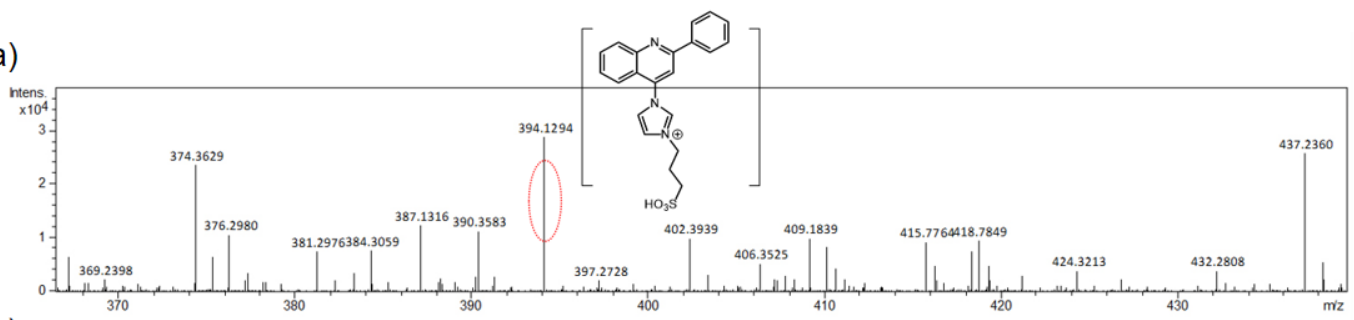

b)

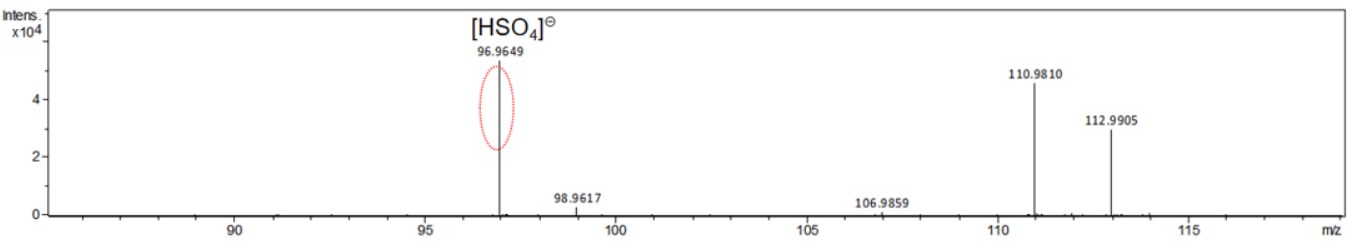

c)

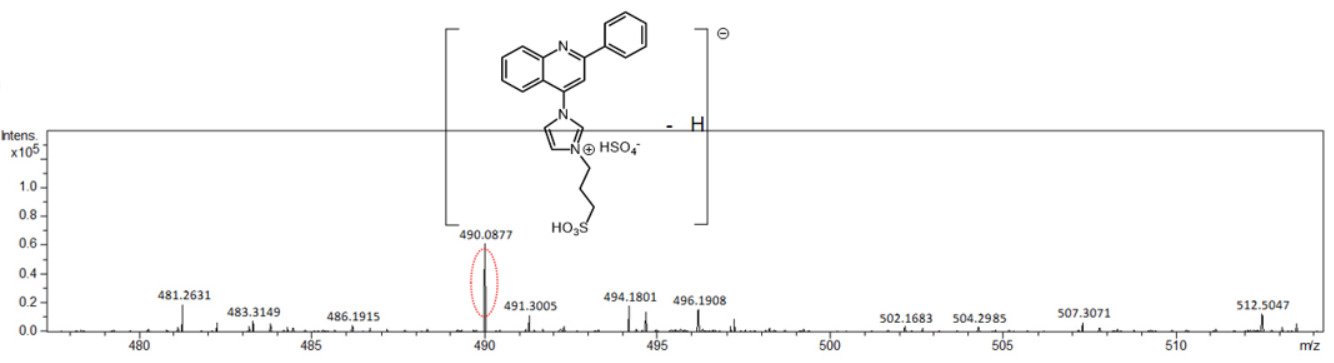

Figure S2. ${ }^{1} \mathrm{H}$ NMR, ${ }^{13} \mathrm{C}$ NMR and MS spectra of model compound B. a) The $\mathrm{m} / \mathrm{z}$ of 394.1294 in the positive HRMS mode belongs to the $[\mathrm{M}]^{+}$peak of the imidazolium cation without $\mathrm{HSO}_{4}^{-}$counter anion. The $\mathrm{m} / \mathrm{z}$

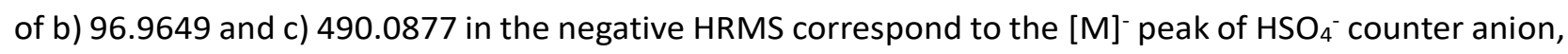
and the $[\mathrm{M}-\mathrm{H}]^{-}$peak of the whole structure of model compound $\mathrm{B}$, respectively. 


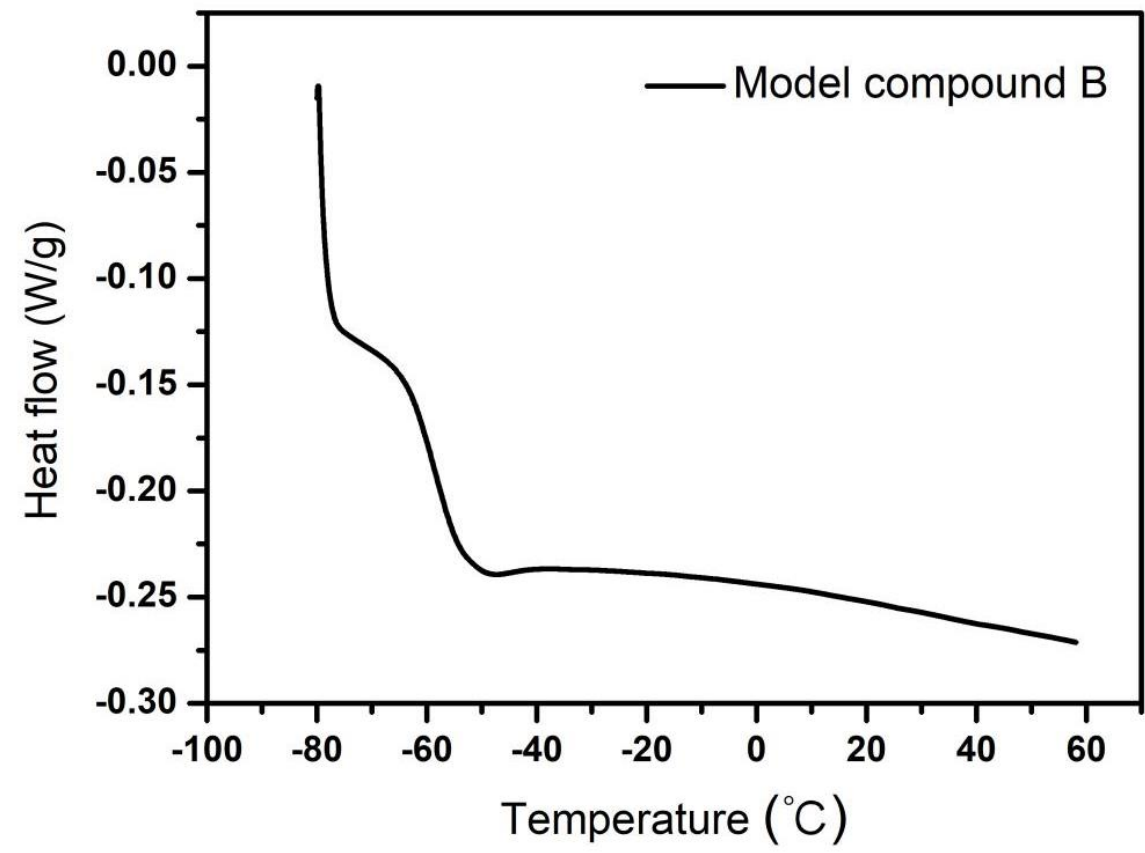

Figure S3. The DSC curve of Model compound B. No real phase transition of melting point was observed except an amorphous glass state transition with a glass transition temperature $\left(T_{\mathrm{g}}\right)$ of $-58.3^{\circ} \mathrm{C}$, which is a typical characteristics of ionic liquids.

\section{Characterization of COF-IM and COF-IM-SO ${ }_{3} \mathrm{H}$}

a)

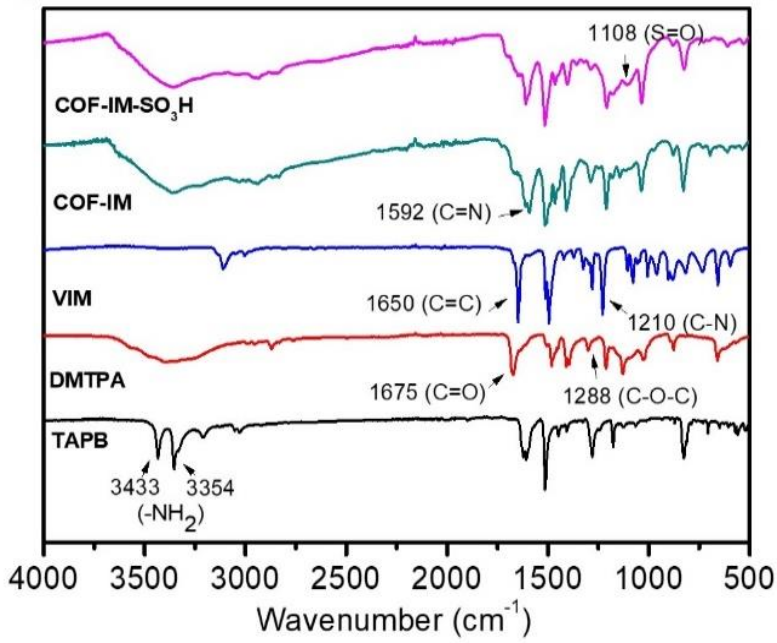

b)

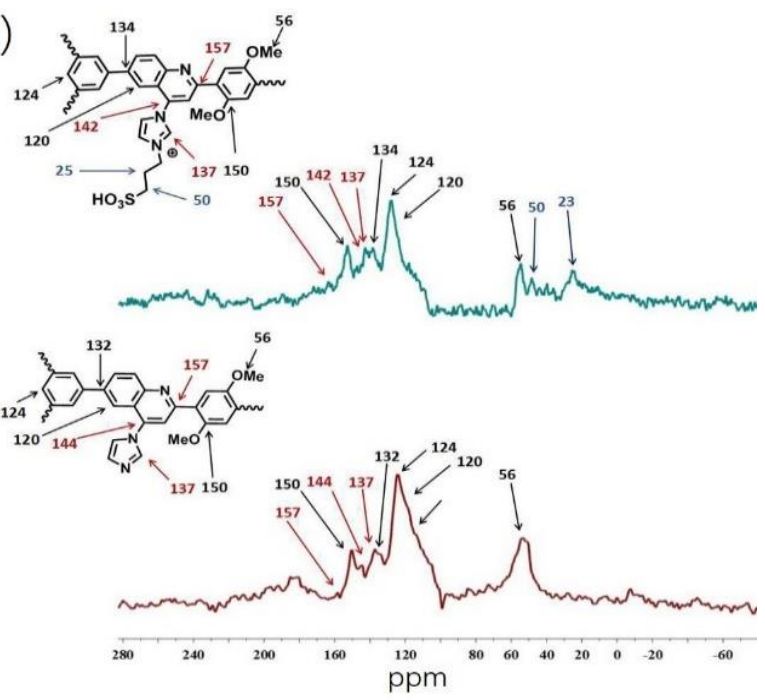

Figure S4. a) IR spectra a) and ${ }^{13} \mathrm{C} N M R$ b) spectra of COF-IM and COF-IM-SO ${ }_{3} \mathrm{H}$. For COF-IM, the typical peaks at 1288 and $1210 \mathrm{~cm}^{-1}$ corresponding to $\mathrm{C}-\mathrm{O}-\mathrm{C}$ and $\mathrm{C}-\mathrm{N}$ in the starting materials were founded in COF-IM. However, the peaks of 3343 and $3354 \mathrm{~cm}^{-1}\left(\mathrm{NH}_{2}\right)$ in TAPB, $1650 \mathrm{~cm}^{-1}(\mathrm{C}=\mathrm{C})$ in VIM, and $1675 \mathrm{~cm}^{-1}(\mathrm{C}=0)$ in DMPTA disappeared in COF-IM; meanwhile, new strong characteristic peak for $\mathrm{C}=\mathrm{N}$ at $1592 \mathrm{~cm}^{-1}$ demonstrated the formation of quinolyl group, which is similar to that of model compound. The solid-state ${ }^{13} \mathrm{C}-\mathrm{MAS}$ NMR spectrum 
of COF-IM exhibited strong signals at ca. $157 \mathrm{ppm}$, which was assignable to the 2-quinolyl carbon atoms in quinoline moiety. The peaks corresponding to the aromatic and imidazole carbons are distributed between 110 and $150 \mathrm{ppm}$. Furthermore, the peaks at 56 and $150 \mathrm{ppm}$ correspond to $-\mathrm{OCH}_{3}$ and the aryl carbon attached to it, respectively.

For COF-IM-SO ${ }_{3} \mathrm{H}$, the peak of $1108 \mathrm{~cm}^{-1}$ belonging to $\mathrm{S}=0$ group appeared. Moreover, the ${ }^{13} \mathrm{C}-\mathrm{CP} / \mathrm{MAS}$ NMR spectrum confirmed the successful formation of the modified pedant structure due to the appearance of additional characteristic peaks at 23-50 ppm belonging to the alkyl group. All these assignments were made based on the model compounds, which was generated via the one-pot model Povarov reaction of aniline, benzaldehyde, and 1-vinylimidazole under the given conditions (Scheme S1, Fig. S1-S2).

a)

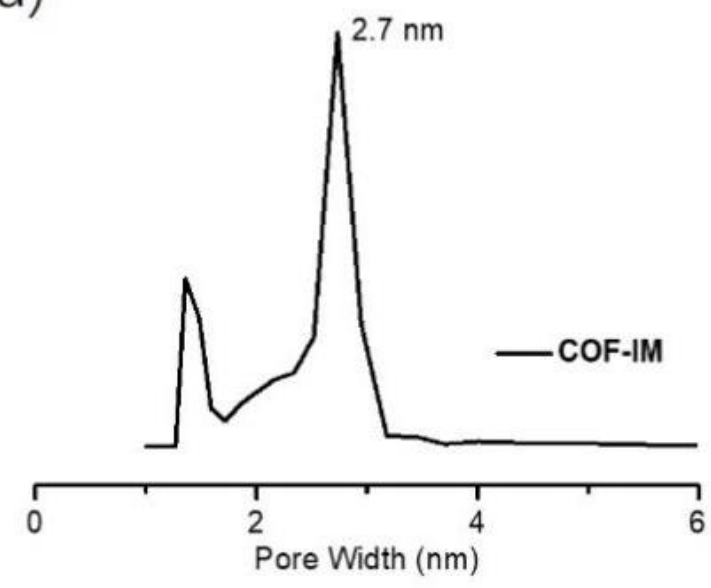

b)

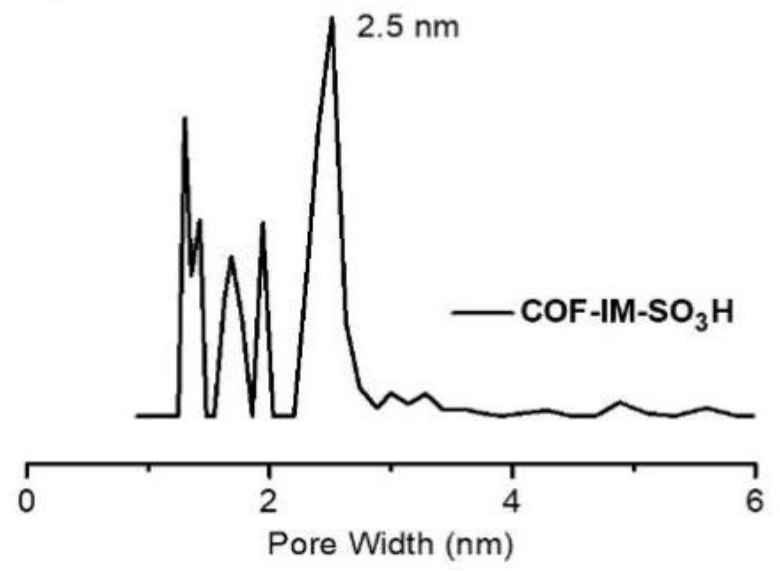

Figure S5. Pore size distribution of COF-IM (a) and COF-IM-SO ${ }_{3} \mathbf{H}(b)$ based on BET data.

a)

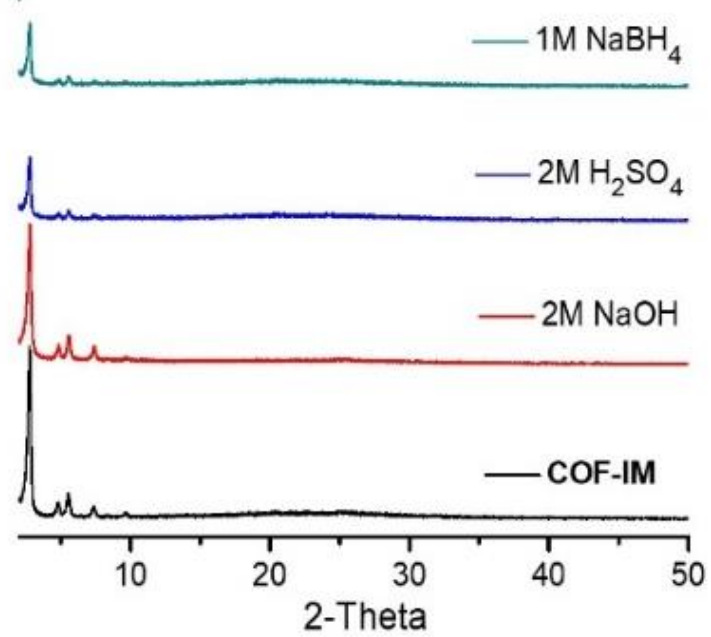

b)

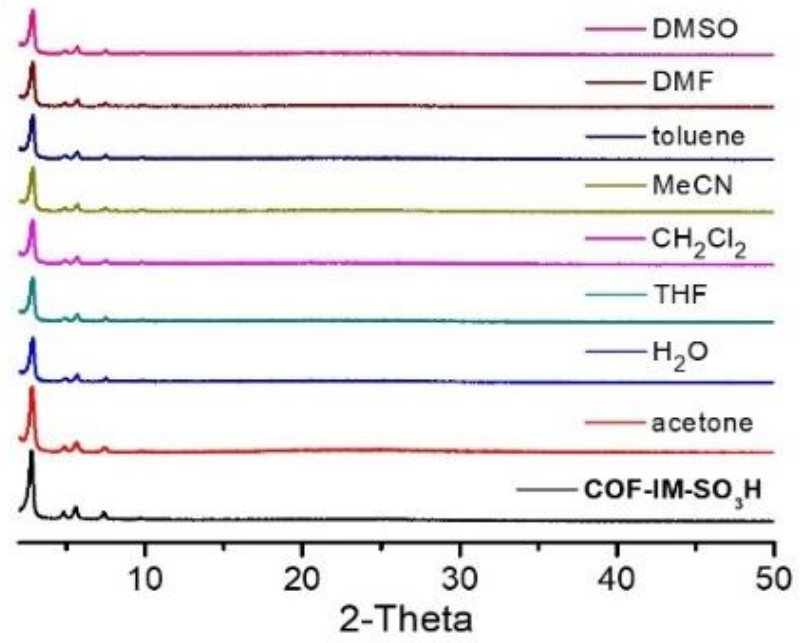

Figure S6. Stability examination of COF-IM (a) and $\mathbf{C O F - I M - S O}{ }_{3} \mathrm{H}$ (b) in different media (soaking in different media for $24 \mathrm{~h}$ ). 
a)

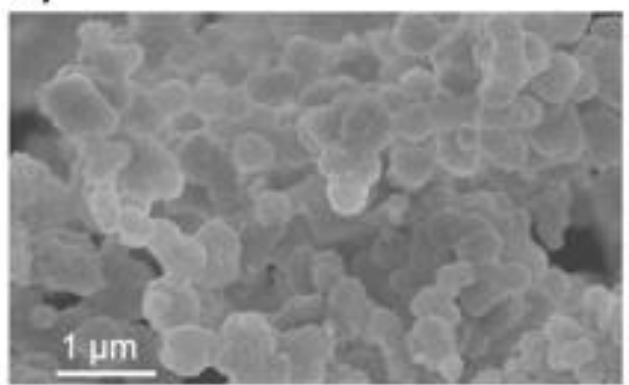

c)

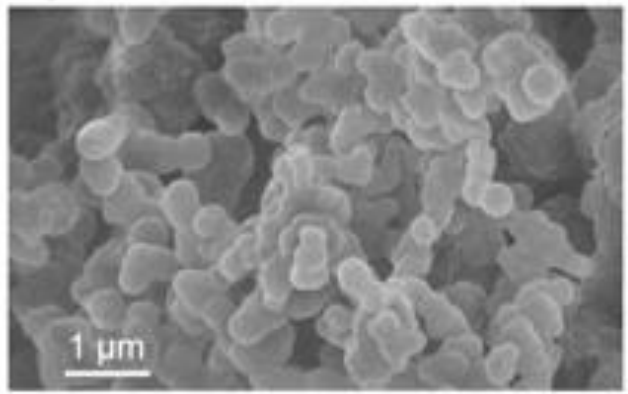

b)

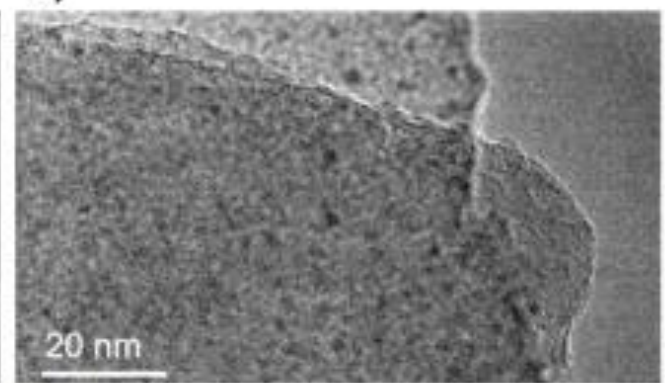

d)

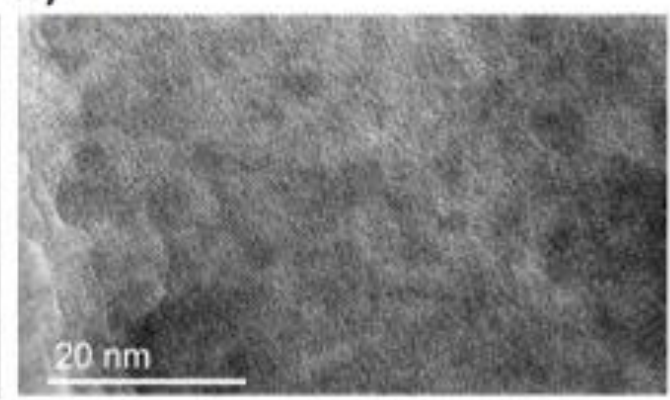

Figure S7. a) SEM images of COF-IM. b) TEM images of COF-IM. c) SEM images of COF-IM-SO ${ }_{3} \mathrm{H}$. d) TEM images of COF-IM-SO ${ }_{3} \mathrm{H}$.
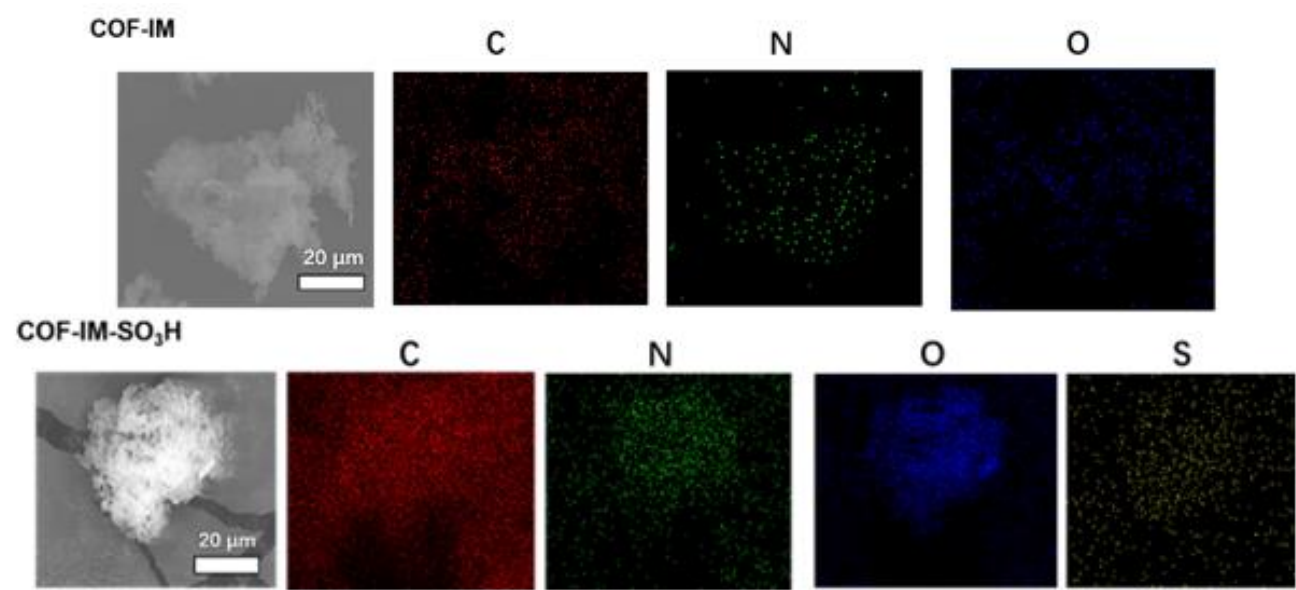

Figure S8. SEM-EDX images of COF-IM (top) and COF-IM-SO ${ }_{3} \mathrm{H}$ (bottom).

\section{Structural modeling of COF-IM}

Crystal structure modeling of COF-IM was generated using the Materials Studio suite of program employing the Crystal Building module. The initial lattice for eclipsed AA stacking models for COF-IM was created by starting with the space group $P 3$ (3D hexagonal), with the parameters of $a=b=36.9554 \AA$ and $c=3.9068 \AA, \alpha=6=90^{\circ}$, $\gamma=120^{\circ}$, approximately predicted from the theoretical unit cell parameters in $P 3$ pace group. Firstly, we degraded the symmetry of lattice to $P 1$, inserted the optimized asymmetric unit segment in the empty cell, and promoted the symmetry to $P 3$, outputting the crude structure of COF-IM. Then the lattice model was geometrically optimized using the Forcite molecular dynamics module (UFF, Ewald summations, QEq_neutral).

The Pawley refinement was performed to optimize the lattice parameters iteratively until the $R_{\mathrm{wp}}$ value converges and the overlay of the observed with refined profiles shows good agreement. i.e., extraction of the integrated intensities was conducted with the powder refinement routine of the Reflex module in Material Studio 
using data from $2 \vartheta=2.0$ to 30 . The profile was calculated starting with the unit cell parameters from the crystal models and the space group $P 3$. The integrated intensities were extracted by a full pattern decomposition using a Thomson-Cox-Hasting pseudo Voigt peak profile, followed by refinement of peak asymmetry using Finger-CoxJephcoat correction. Unit cells and zero-shift were then refined with peak asymmetry. Once this was achieved, the background was refined with 20th-order polynomial. Refinement of unit cell parameters, zero shift, peak asymmetry, crystallite size and strain were used for the final profile.

Table S1. Fractional atomic coordinates for the unit cell of COF-IM. The initial lattice was created by starting with the space group $P 3$.

AA space group: $P 3$

$a=b=36.9554 \AA, c=3.9068 \AA, \alpha=6=90.0^{\circ}, \gamma=120^{\circ}, R \mathrm{wp}=4.33 \%, R p=3.36 \%$

\begin{tabular}{|c|c|c|c|c|c|c|c|}
\hline Atom & $x$ & y & $z$ & Atom & $x$ & $y$ & $z$ \\
\hline $\mathrm{C} 1$ & 0.04496 & -0.97486 & -0.47183 & N35 & 0.17349 & -0.9999 & -0.25396 \\
\hline $\mathrm{C} 2$ & 0.0191 & -0.95667 & -0.46735 & N36 & 0.49603 & -0.66694 & -0.75362 \\
\hline C3 & 0.08945 & -0.95014 & -0.49475 & C37 & 0.1389 & -1.03436 & -0.3684 \\
\hline C4 & 0.1092 & -0.91053 & -0.6594 & C38 & 0.1379 & -1.06936 & -0.23039 \\
\hline C5 & 0.15282 & -0.88643 & -0.68713 & N39 & 0.1718 & -1.05656 & -0.03456 \\
\hline C6 & 0.17782 & -0.90248 & -0.57001 & $\mathrm{C} 40$ & 0.19294 & -1.01463 & -0.05015 \\
\hline $\mathrm{C7}$ & 0.15987 & -0.94295 & -0.42301 & C41 & 0.47761 & -0.64485 & -0.65687 \\
\hline $\mathrm{C} 8$ & 0.11616 & -0.96442 & -0.36577 & $\mathrm{C} 42$ & 0.50051 & -0.60474 & -0.78674 \\
\hline C9 & 0.18683 & -0.95918 & -0.3438 & N43 & 0.53265 & -0.60225 & -0.96327 \\
\hline $\mathrm{C} 10$ & 0.23041 & -0.93199 & -0.38242 & C44 & 0.52956 & -0.64003 & -0.94246 \\
\hline C11 & 0.247 & -0.89113 & -0.5106 & $\mathrm{H} 45$ & 0.03309 & -0.92498 & -0.4651 \\
\hline N12 & 0.21976 & -0.87849 & -0.60359 & $\mathrm{H} 46$ & 0.09218 & -0.89864 & -0.76748 \\
\hline $\mathrm{C} 13$ & 0.2903 & -0.86298 & -0.54105 & $\mathrm{H} 47$ & 0.16629 & -0.85756 & -0.79913 \\
\hline C14 & 0.30652 & -0.82138 & -0.42529 & $\mathrm{H} 48$ & 0.1035 & -0.99137 & -0.22501 \\
\hline C15 & 0.34964 & -0.79224 & -0.43356 & $\mathrm{H} 49$ & 0.25082 & -0.94189 & -0.32078 \\
\hline C16 & 0.37744 & -0.80474 & -0.56501 & $\mathrm{H} 50$ & 0.28672 & -0.81224 & -0.32759 \\
\hline $\mathrm{C} 17$ & 0.36129 & -0.84604 & -0.68656 & H51 & 0.38122 & -0.85501 & -0.78399 \\
\hline $\mathrm{C} 18$ & 0.31814 & -0.87523 & -0.67775 & H52 & 0.41995 & -0.72626 & -0.79802 \\
\hline C19 & 0.42089 & -0.77699 & -0.56825 & H53 & 0.56711 & -0.67054 & -0.60452 \\
\hline N2O & 0.44644 & -0.78985 & -0.43617 & H54 & 0.56976 & -0.76967 & -0.0973 \\
\hline $\mathrm{C} 21$ & 0.4884 & -0.76515 & -0.41503 & H55 & 0.49605 & -0.81158 & -0.16718 \\
\hline $\mathrm{C} 22$ & 0.50831 & -0.72337 & -0.53695 & H56 & 0.63244 & -0.7417 & -0.33986 \\
\hline $\mathrm{C} 23$ & 0.48258 & -0.7077 & -0.66732 & H57 & 0.32576 & -0.74983 & 0.05642 \\
\hline $\mathrm{C} 24$ & 0.43907 & -0.73582 & -0.69236 & H58 & 0.32329 & -0.73031 & -0.35219 \\
\hline $\mathrm{C} 25$ & 0.55241 & -0.70006 & -0.51064 & H59 & 0.36704 & -0.70098 & -0.08361 \\
\hline $\mathrm{C} 26$ & 0.57696 & -0.71563 & -0.35845 & $\mathrm{H} 60$ & 0.3422 & -0.91762 & -1.16917 \\
\hline $\mathrm{C} 27$ & 0.55472 & -0.75689 & -0.22522 & H61 & 0.3016 & -0.96649 & -1.02325 \\
\hline $\mathrm{C} 28$ & 0.51121 & -0.78166 & -0.25984 & $\mathrm{H} 62$ & 0.34549 & -0.93637 & -0.75919 \\
\hline $\mathrm{C} 29$ & 0.62159 & -0.69118 & -0.3436 & $\mathrm{H} 63$ & 0.11704 & -1.03538 & -0.53573 \\
\hline C30 & 0.64689 & -0.71 & -0.34068 & $\mathrm{H} 64$ & 0.11542 & -1.09969 & -0.27283 \\
\hline 031 & 0.36535 & -0.75246 & -0.30991 & H65 & 0.22023 & -0.99682 & 0.08004 \\
\hline C32 & 0.34407 & -0.73247 & -0.16543 & H66 & 0.45142 & -0.65527 & -0.50848 \\
\hline 033 & 0.30276 & -0.91499 & -0.80042 & H67 & 0.49412 & -0.5811 & -0.75297 \\
\hline C34 & 0.32431 & -0.93475 & -0.94487 & H68 & 0.55043 & -0.64652 & -1.05858 \\
\hline
\end{tabular}




\section{Catalytic Biginelli Reaction over COF-IM-SO ${ }_{3} \mathrm{H}$}

The model Biginelli reaction performed in organic solvents and water gave lower yields (Figure S8).

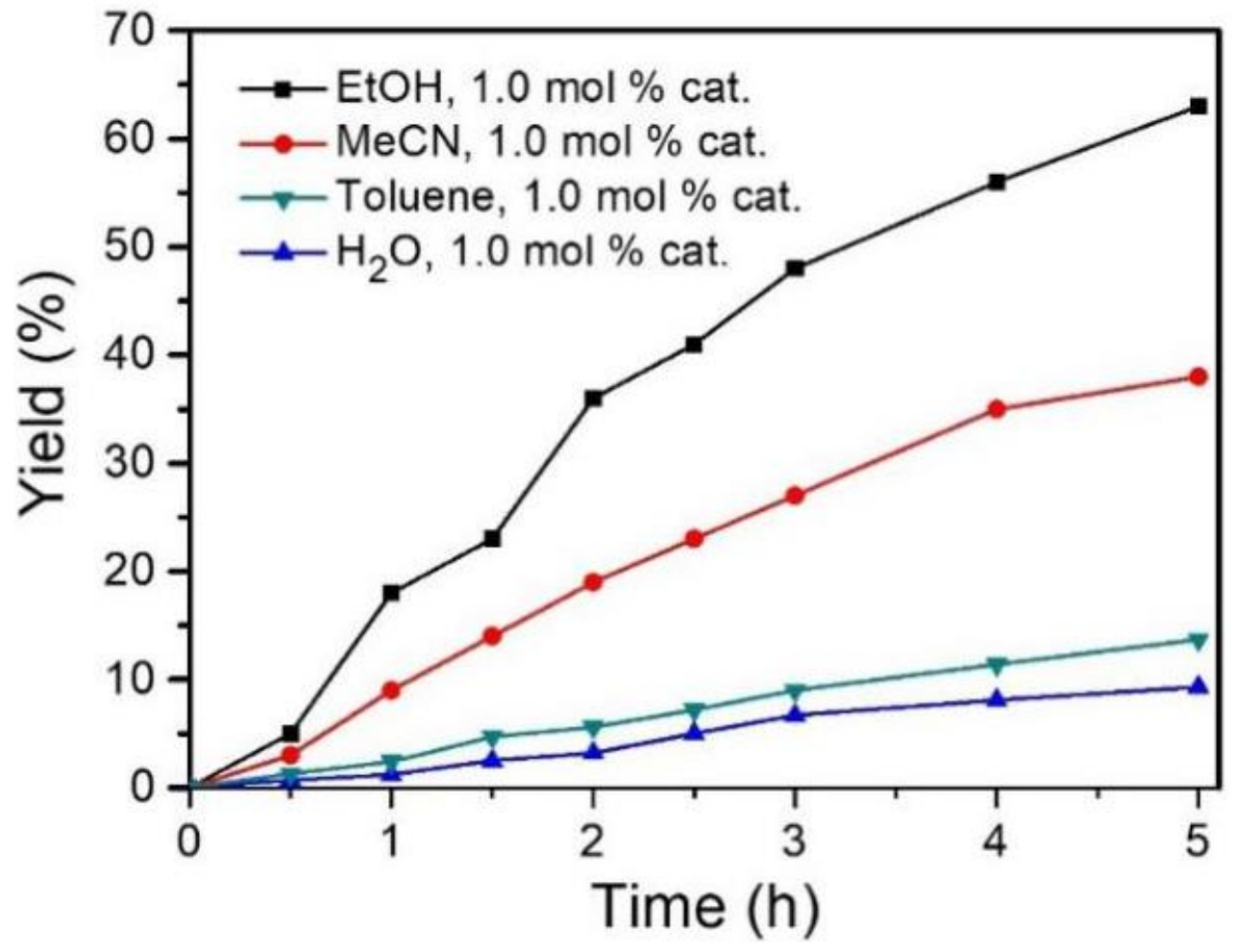

Figure 59. Time examination of the model Biginelli reaction conducted in different media under reflux condition.

Table S2. Effect of various Catalyst for the model reaction.

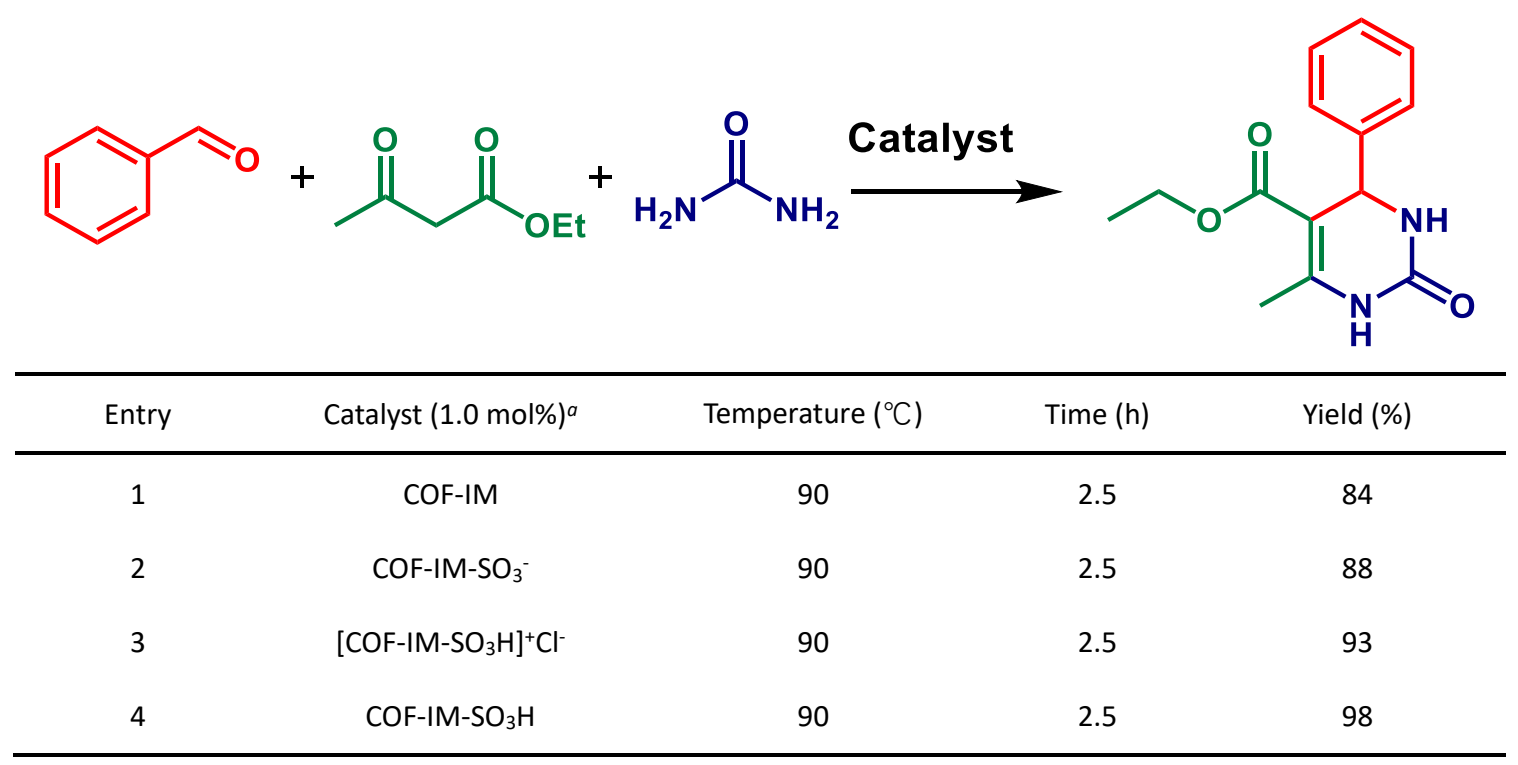

${ }^{a}$ The COF-IM-SO ${ }_{3}^{-}$is synthesized from COF-IM and 1,3-propanesultone without subsequent acidification; [COF$\left.\mathrm{IM}-\mathrm{SO}_{3} \mathrm{H}\right]^{+} \mathrm{Cl}^{-}$is obtained by acidifying $\mathrm{COF}-\mathrm{IM}^{-} \mathrm{SO}_{3}{ }^{-}$with hydrochloric acid $(0.1 \mathrm{mM}, \mathrm{pH}=4)$. 
Table S3. Summary of the reported heterogeneous catalysts for Biginelli reaction

\begin{tabular}{|c|c|c|c|c|c|c|c|}
\hline en & catalyst & $\begin{array}{l}\text { catalyst } \\
\text { amount }\end{array}$ & conditions & $\mathrm{T}\left({ }^{\circ} \mathrm{C}\right)$ & $t(h)$ & yield (\%) & Ref. \\
\hline 1 & $\mathrm{PsMImPF}_{6}$ & $3.5 \mathrm{~mol} \%$ & $\mathrm{AcOH}$ & 100 & 2 & 98 & 15 \\
\hline 2 & $\mathrm{SiO}_{2}-\mathrm{NaHSO}_{4}$ & $10 \mathrm{~mol} \%$ & $\mathrm{MeCN}$ & reflux & 1.5 & 93 & 16 \\
\hline 3 & $\mathrm{Al}_{2} \mathrm{O}_{3}-\mathrm{CH}_{3} \mathrm{SO}_{3} \mathrm{H}$ & $15 \mathrm{~mol} \%$ & solvent -free & 120 & 2.1 & 88 & 17 \\
\hline 4 & $\mathrm{~F}_{3} \mathrm{C} . \mathrm{SO}_{3} \mathrm{H}-\mathrm{Al}_{2} \mathrm{O}_{3}$ & $5 \mathrm{~mol} \%$ & solvent -free & 120 & 0.5 & 90 & 18 \\
\hline 5 & $\mathrm{BIL}-\mathrm{SO}_{3} \mathrm{H}$ & $2.5 \mathrm{~mol} \%$ & EtOH & 80 & 3 & 98 & 19 \\
\hline 6 & calix[4]arene sulfonic acid & $0.5 \mathrm{~mol} \%$ & $\mathrm{EtOH}$ & reflux & 8 & 81 & 20 \\
\hline 7 & silica sulfuric acid & $30 \mathrm{~mol} \%$ & solvent -free & 60 & 2 & 96 & 21 \\
\hline 8 & $\mathrm{PPF}-\mathrm{SO}_{3} \mathrm{H}$ & $1 \mathrm{~mol} \%$ & EtOH & reflux & 8 & 81 & 22 \\
\hline 9 & $\mathrm{PANI}^{-\mathrm{HBF}_{4}-\mathrm{DHS}}$ & 5 wt $\%$ & $\mathrm{EtOH}$ & reflux & 6 & 97 & 23 \\
\hline 10 & PS-PEG-SO ${ }_{3} \mathrm{H}$ & $0.3 \mathrm{~g}$ & dioxane/isopropanol & 80 & 10 & 80 & 24 \\
\hline 11 & $\mathrm{HCl}-\beta-\mathrm{CD}$ & $10 \mathrm{~mol} \%$ & $\mathrm{EtOH}$ & reflux & 8 & 92 & 25 \\
\hline 12 & $\mathrm{CD}-\mathrm{SO}_{3} \mathrm{H}$ & $0.04 \mathrm{~g}$ & solvent -free & 100 & 2 & 89 & 26 \\
\hline 13 & $\mathrm{MCN}-41-\mathrm{R}-\mathrm{SO}_{3} \mathrm{H}$ & $0.1 \mathrm{~g}$ & $\mathrm{MeCN}$ & reflux & 6 & 92 & 27 \\
\hline 14 & $\mathrm{H}_{2} \mathrm{SO}_{4} / \mathrm{SiO}_{2}$ & $0.9 \mathrm{~g}$ & n-hexane & reflux & 7.2 & 95 & 28 \\
\hline 15 & $\mathrm{H}_{3} \mathrm{PW}_{12} \mathrm{O}_{40}$ & $2 \mathrm{~mol} \%$ & acetic acid & reflux & $6-7$ & 75 & 29 \\
\hline 16 & $\mathrm{H}_{6} \mathrm{P}_{2} \mathrm{~W}_{18} \mathrm{O}_{62} \cdot 24 \mathrm{H}_{2} \mathrm{O}$ & $1 \mathrm{~g}$ & solvent -free & 80 & 1.5 & 83 & 30 \\
\hline 17 & $\mathrm{H}_{3} \mathrm{PW}_{12} \mathrm{O}_{40}-\mathrm{KSF}$ & $0.4 \mathrm{~g}$ & $\mathrm{MeCN}$ & reflux & 4 & 92 & 31 \\
\hline 18 & Montmorillonite $\mathrm{K} 10-\mathrm{H}_{3} \mathrm{PW}_{12} \mathrm{O}_{40}$ & $0.4 \mathrm{~g}$ & $\mathrm{MeCN}$ & reflux & 4.5 & 90 & 32 \\
\hline 19 & $\mathrm{Fe}_{3} \mathrm{O}_{4} @ \mathrm{SiO}_{2} @ \mathrm{~N}\left(\mathrm{SO}_{3} \mathrm{H}\right)-\mathrm{NH}\left(\mathrm{SO}_{3} \mathrm{H}\right)$ & $0.01 \mathrm{~g}$ & solvent -free & 100 & 0.5 & 85 & 33 \\
\hline 20 & MNP-L-proline- $\mathrm{SO}_{3} \mathrm{H}$ & $0.075 \mathrm{~g}$ & solvent -free & 100 & 3 & 89 & 34 \\
\hline 21 & MWCNTs- $\mathrm{SO}_{3} \mathrm{H}$ & $0.005 \mathrm{~g}$ & solvent -free & 120 & 25 & 90 & 35 \\
\hline 22 & Bentonite/PS- $\mathrm{SO}_{3} \mathrm{H}$ & $0.1 \mathrm{~g}$ & solvent -free & 120 & 0.5 & 89 & 36 \\
\hline 23 & Zn-MOF & $10 w t \%$ & solvent -free & 60 & 2 & 93 & 37 \\
\hline 24 & COF-IM-SO ${ }_{3} \mathrm{H}$ & $1.0 \mathrm{~mol} \%$ & solvent -free & 90 & 2.5 & 98 & $\begin{array}{l}\text { this } \\
\text { work }\end{array}$ \\
\hline
\end{tabular}




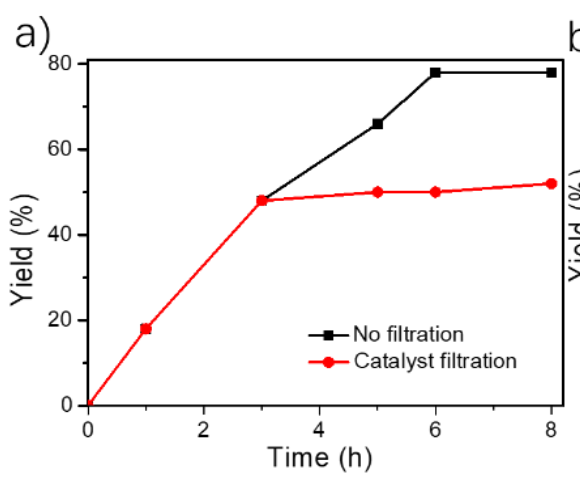

b)

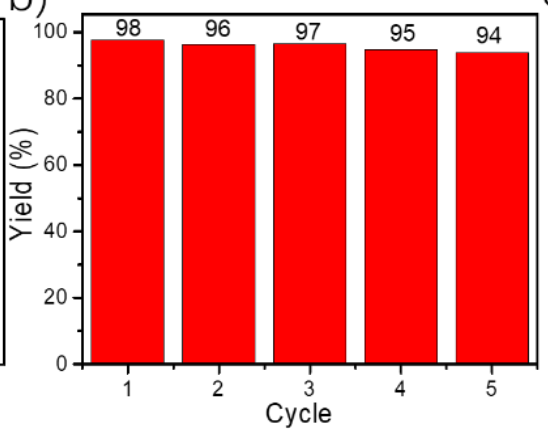

C)

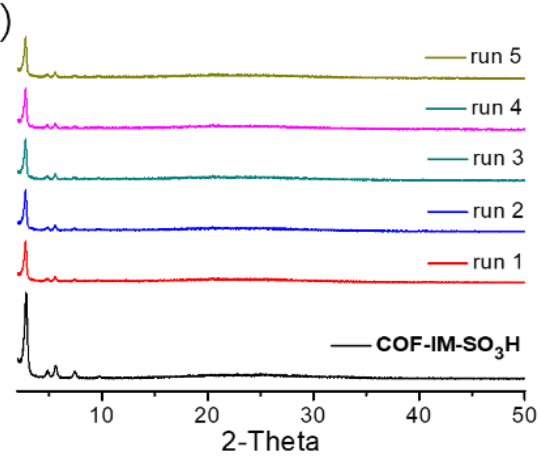

d)
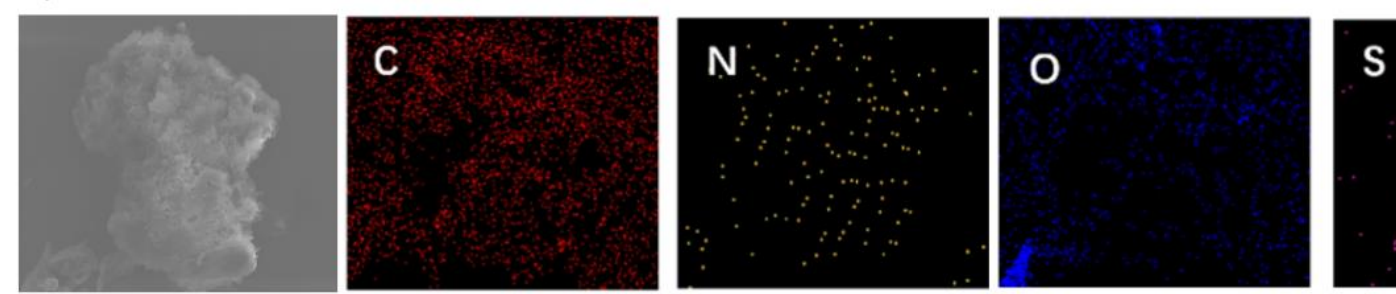

Figure S10. a) Hot leaching test of $\mathrm{COF}-\mathbf{I M}-\mathrm{SO}_{3} \mathrm{H}$ for the model Biginelli reaction. b) Catalytic cycles. c) PXRD patterns of COF-IM-SO ${ }_{3} \mathrm{H}$ and after five catalytic cycles. d) SEM image after five catalytic cycles. e) SEM-EDX spectra after five catalytic cycles.

a)

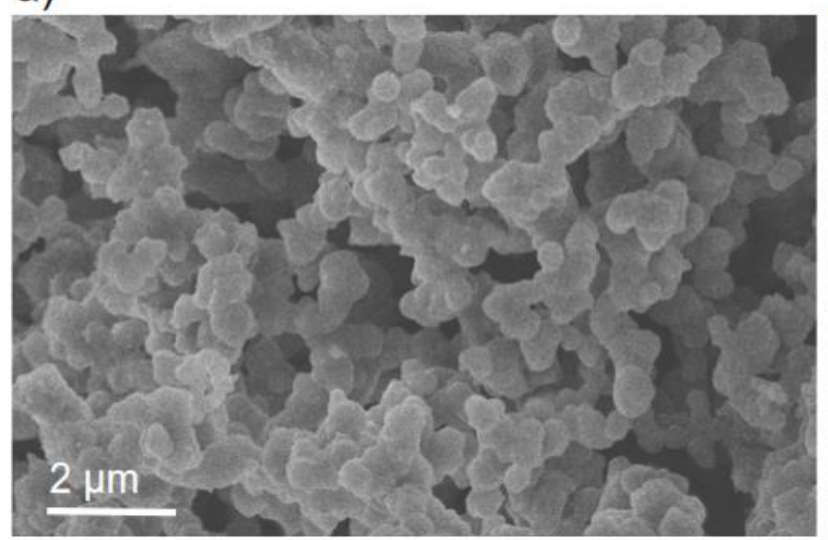

b)

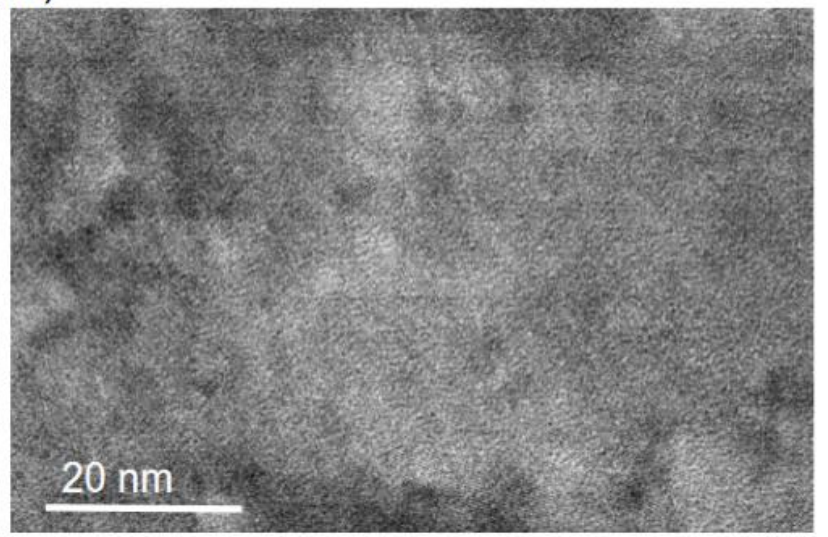

Figure S11. a) SEM image, b) TEM image of $\mathrm{COF}-\mathrm{IM}-\mathrm{SO}_{3} \mathrm{H}$ after five catalytic cycles.

Table S4. Elemental analysis of COF-IM-SO ${ }_{3} \mathrm{H}$ before and after five catalytic runs

\begin{tabular}{|c|c|c|c|c|c|}
\hline COF-IM-SO ${ }_{3} \mathrm{H}$ & $C(\%)$ & $N(\%)$ & $H(\%)$ & $O(\%)$ & $S(\%)$ \\
\hline Before & 67.39 & 12.14 & 4.76 & 11.28 & 3.75 \\
\hline After & 67.12 & 12.03 & 4.89 & 11.6 & 3.73 \\
\hline
\end{tabular}


<smiles>CCOC(=O)C1=C(C)NC(=O)NC1c1ccccc1</smiles>

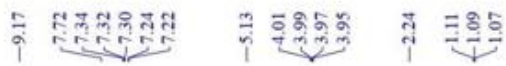

4a: 1 H NMR

$\left(400 \mathrm{MHz}, \mathrm{DMSO}-d_{6}\right)$
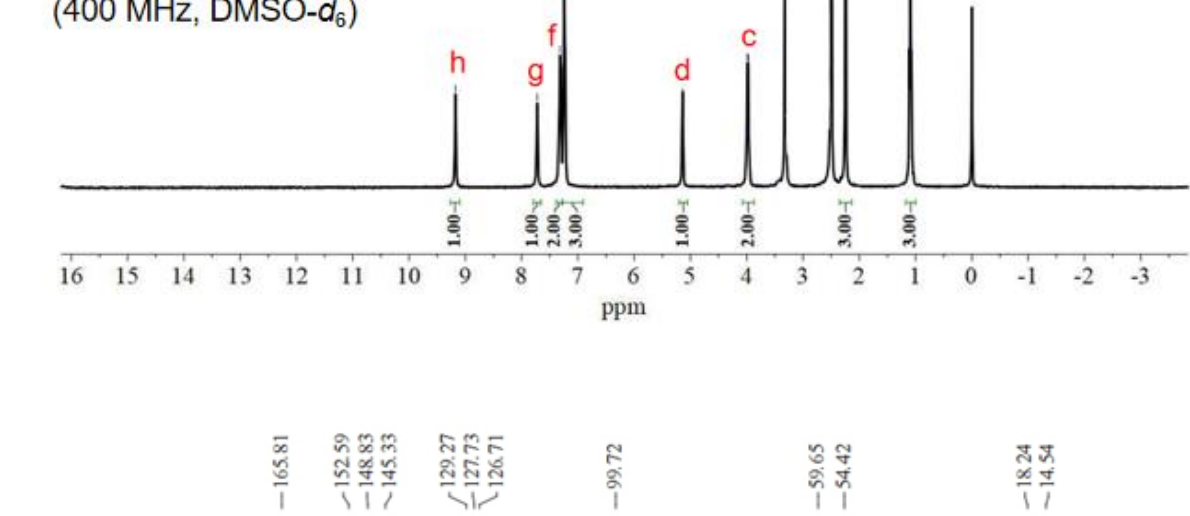<smiles>CCOC(=O)C1=C(C)NC(=O)NC1c1ccccc1</smiles>

4a: ${ }^{13} \mathrm{C}\left\{{ }^{1} \mathrm{H}\right\} \mathrm{NMR}$

$\left(100 \mathrm{MHz}, \mathrm{DMSO}-d_{6}\right)$
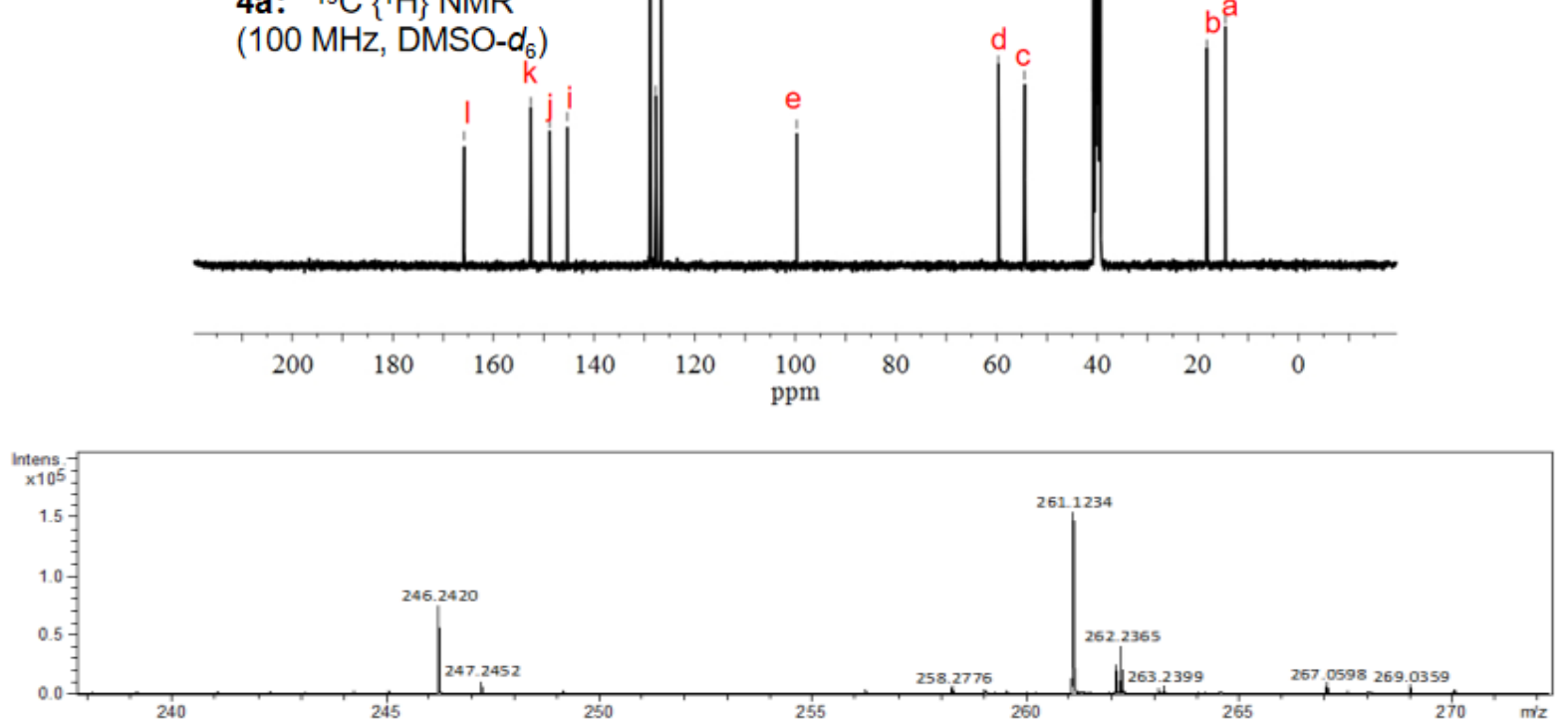

Figure S12. ${ }^{1} \mathrm{H}$ and ${ }^{13} \mathrm{C}$ NMR, and MS spectra for 5-ethoxycarbonyl-6-methyl-4-phenyl-3,4-2(1H)-one (Table 1 , entry $1,4 a)$. 


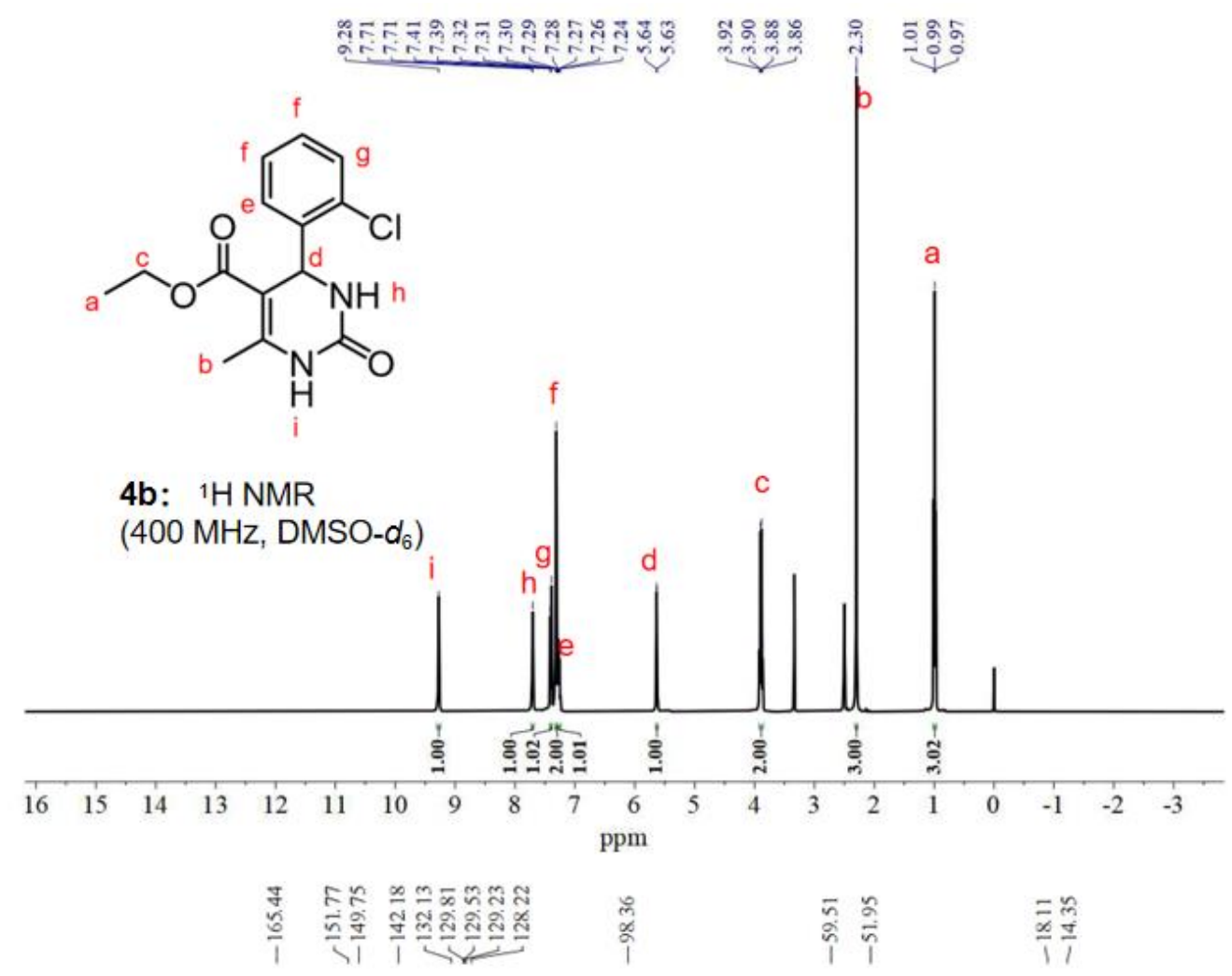<smiles>CCOC(=O)C1=C(C)NC(=O)NC1c1ccccc1Cl</smiles>

4b: ${ }^{13} \mathrm{C}\left\{{ }^{1} \mathrm{H}\right\} \mathrm{NMR}$ $\left(100 \mathrm{MHz}, \mathrm{DMSO}-d_{6}\right)$
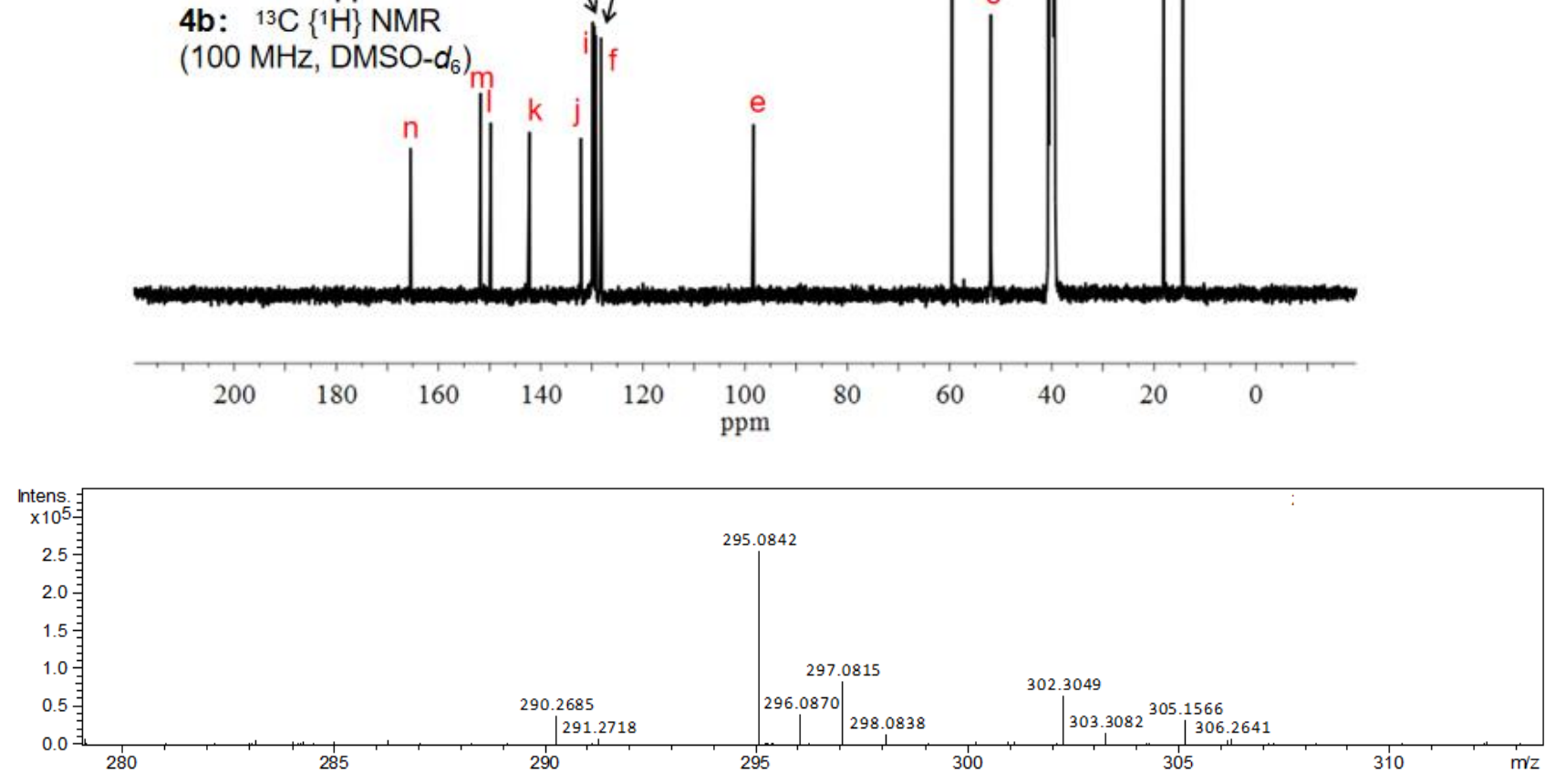

Figure S13. ${ }^{1} \mathrm{H}$ and ${ }^{13} \mathrm{C}$ NMR, and MS spectra for 5-(ethoxycarbonyl)-6-methyl-4-(2-chlorophenyl)-3,4dihydropyrimidin-2(1H)-one (Table 1 , entry $2, \mathbf{4 b}$ ). 

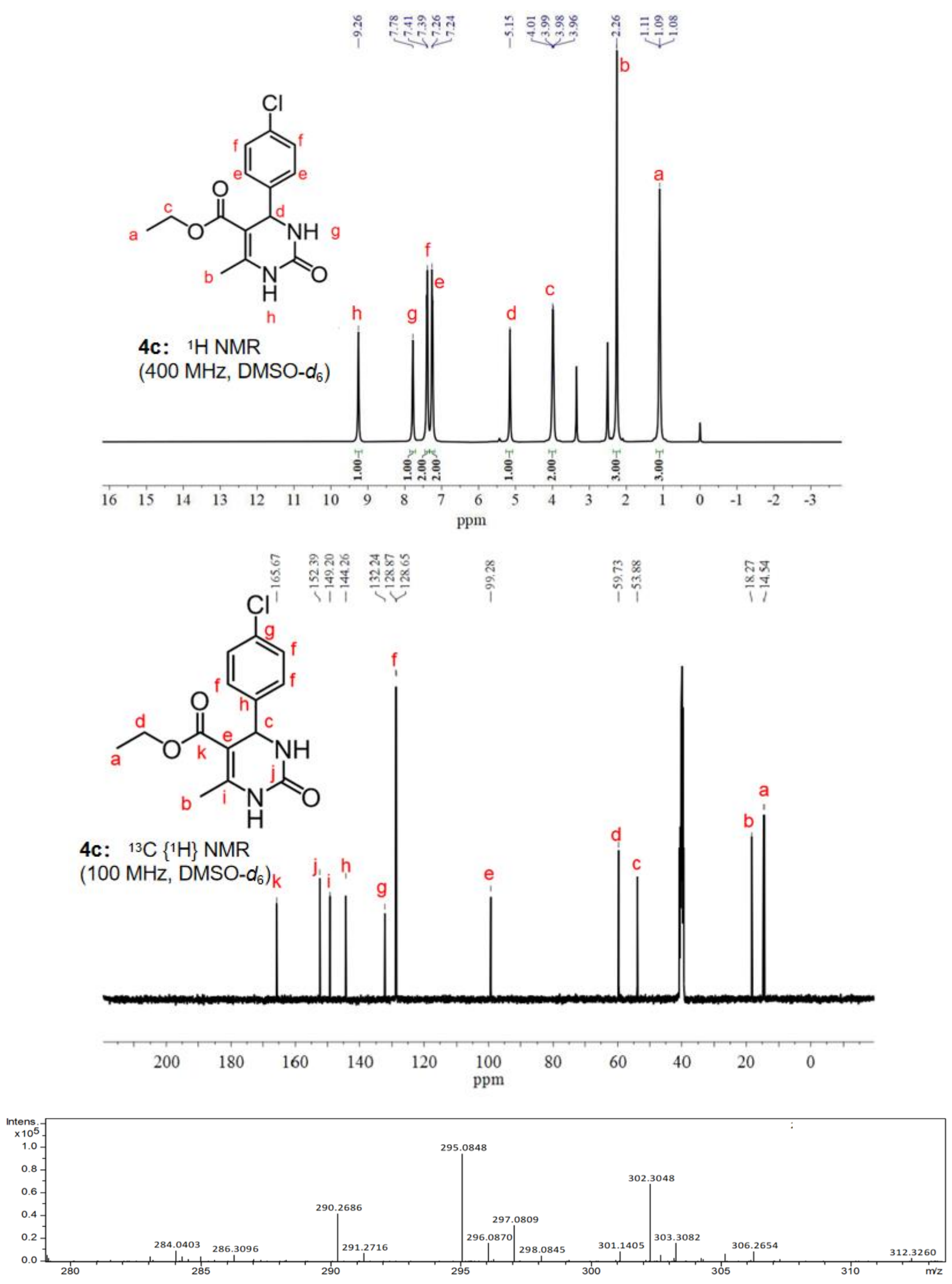

Figure S14. ${ }^{1} \mathrm{H}$ and ${ }^{13} \mathrm{C}$ NMR, and MS spectra for 5-(ethoxycarbonyl)-6-methyl-4-(4-chlorophenyl)-3,4dihydropyrimidin-2(1H)-one (Table 1, entry 3, 4c). 

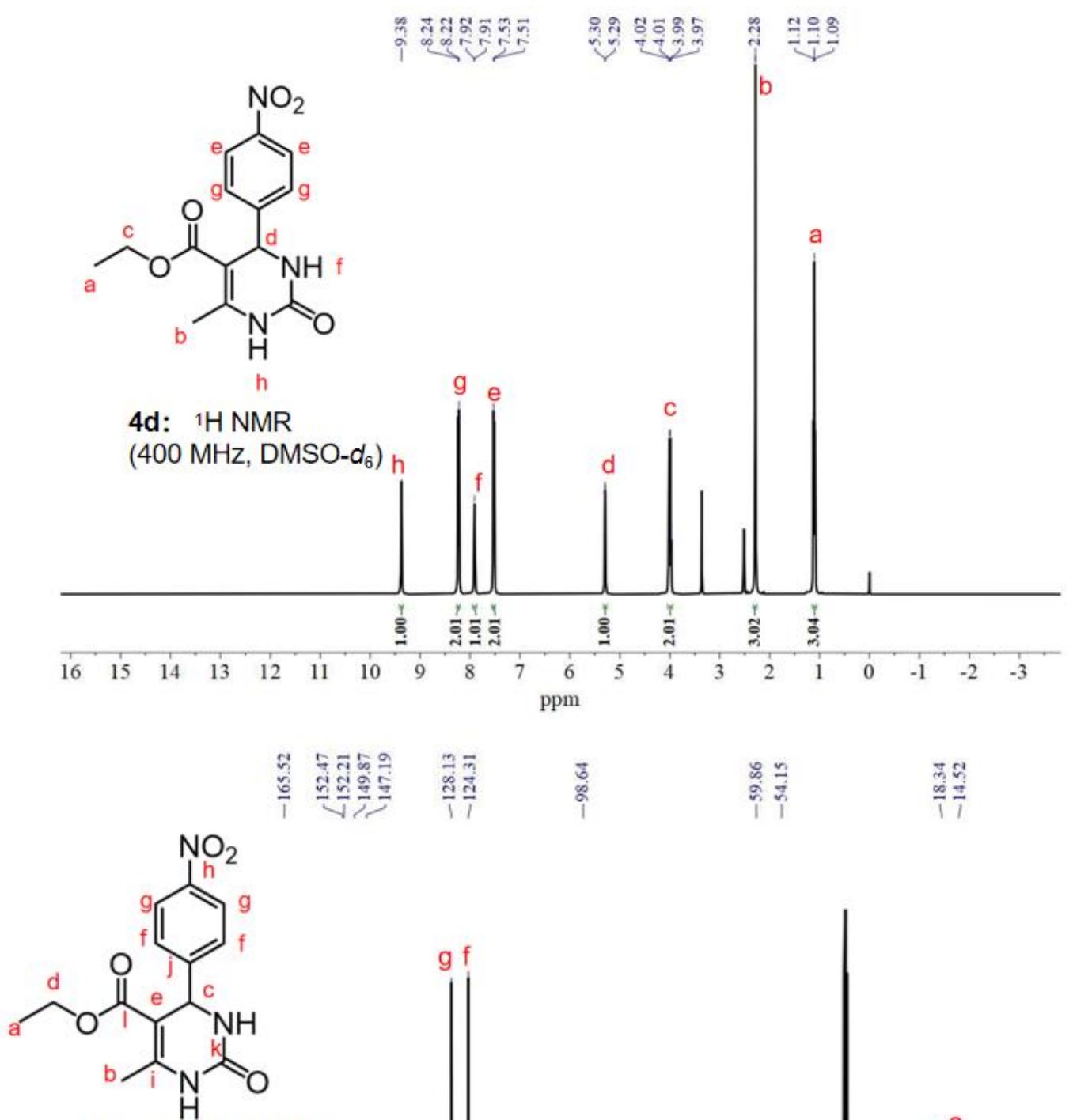

4d: ${ }^{13} \mathrm{C}\left\{{ }^{1} \mathrm{H}\right\}$ NMR $\left(100 \mathrm{MHz}, \mathrm{DMSO}-d_{6}\right)$

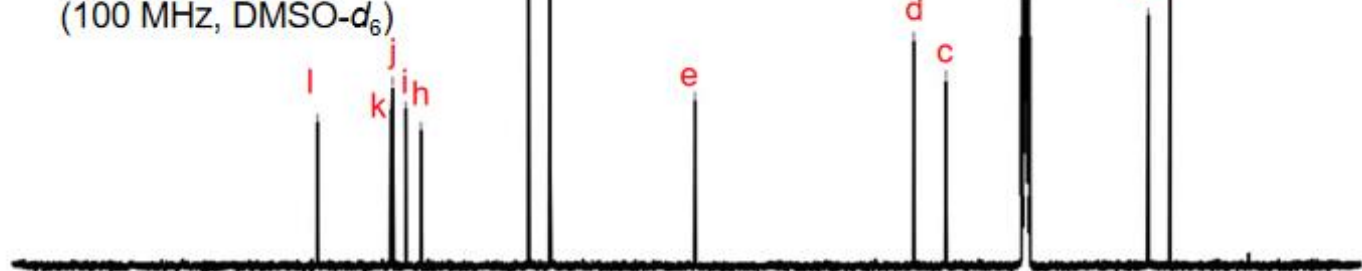

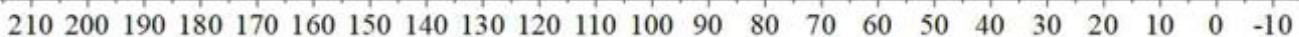
ppm

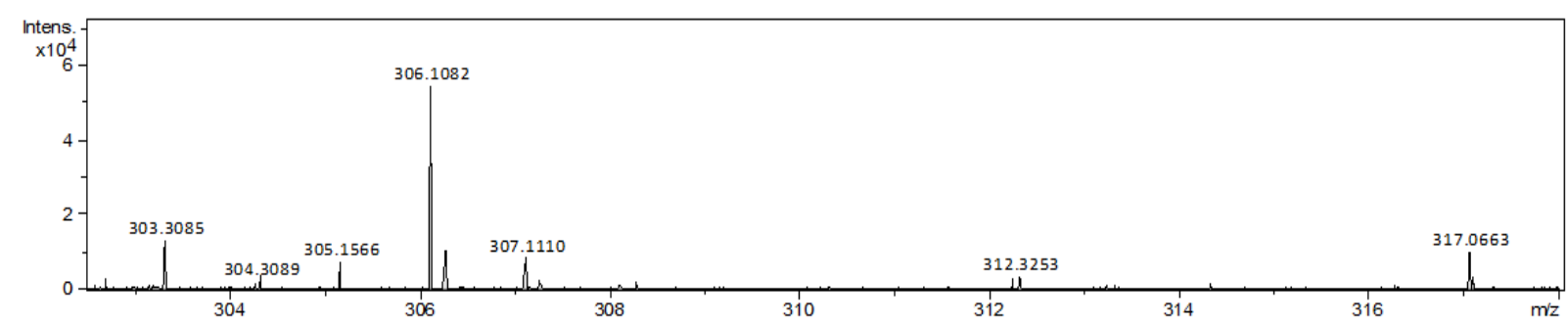

Figure S15. ${ }^{1} \mathrm{H}$ and ${ }^{13} \mathrm{C} \quad \mathrm{NMR}$, and $\mathrm{MS}$ spectra for 5-(ethoxycarbonyl)-6-methyl-4-(4-nitrophenyl)-3,4dihydropyrimidin-2(1H)-one (Table 1, entry 4, 4d). 
<smiles>CCOC(=O)C1=C(C)NC(=O)NC1c1ccc(C)cc1</smiles>

4e: ${ }^{1} \mathrm{H} N M R$

$\left(400 \mathrm{MHz}, \mathrm{DMSO}-\mathrm{d}_{6}\right)$
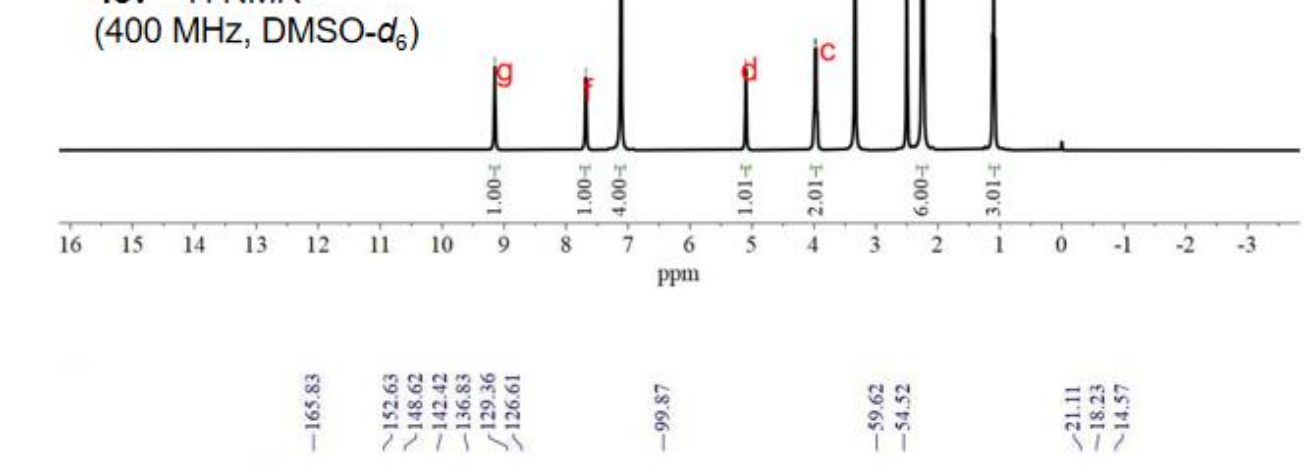<smiles>CCOC(=O)C1=C(C)NC(=O)NC1c1ccc(C)cc1</smiles>

4e: ${ }^{13} \mathrm{C}\left\{{ }^{1} \mathrm{H}\right\} \mathrm{NMR}$ $\left(100 \mathrm{MHz}, \mathrm{DMSO}-\mathrm{d}_{6}\right)$ ।

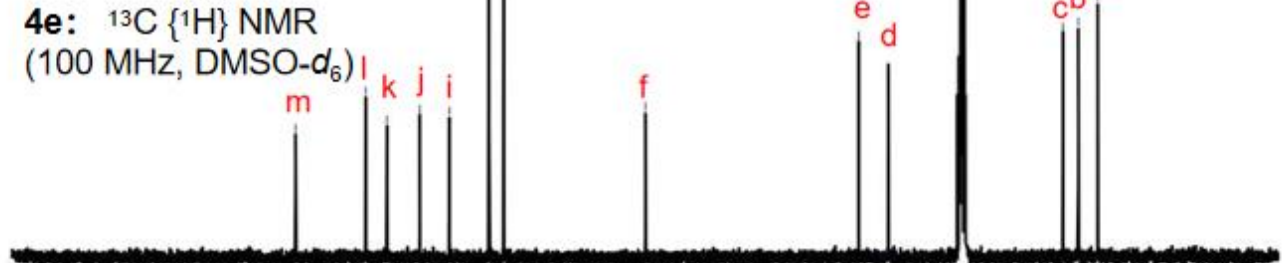

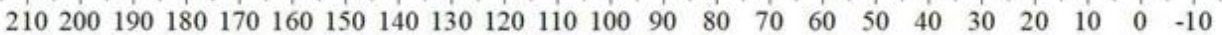
ppm

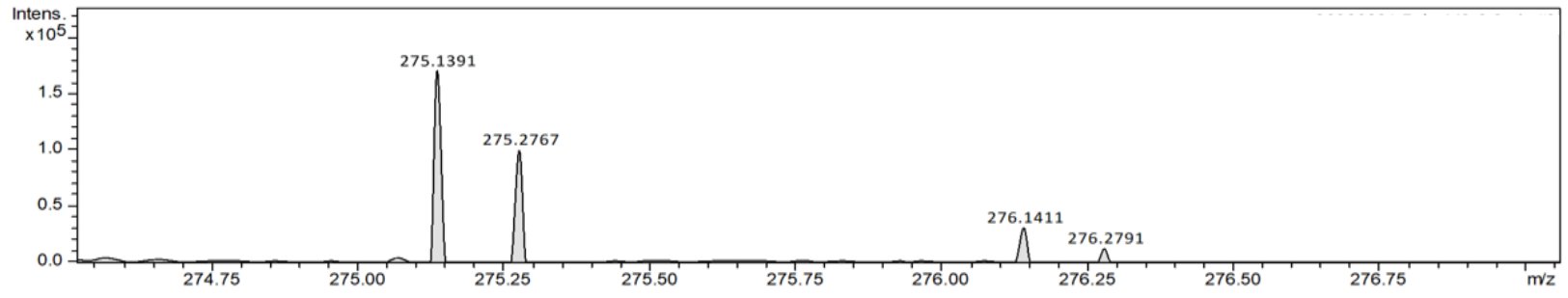

Figure S16. ${ }^{1} \mathrm{H}$ and ${ }^{13} \mathrm{C} \mathrm{NMR}$, and $\mathrm{MS}$ spectra for 5-(ethoxycarbonyl)-6-methyl-4-(4-methylphenyl)-3,4dihydropyrimidin-2(1H)-one (Table 1 , entry 5, 4e). 

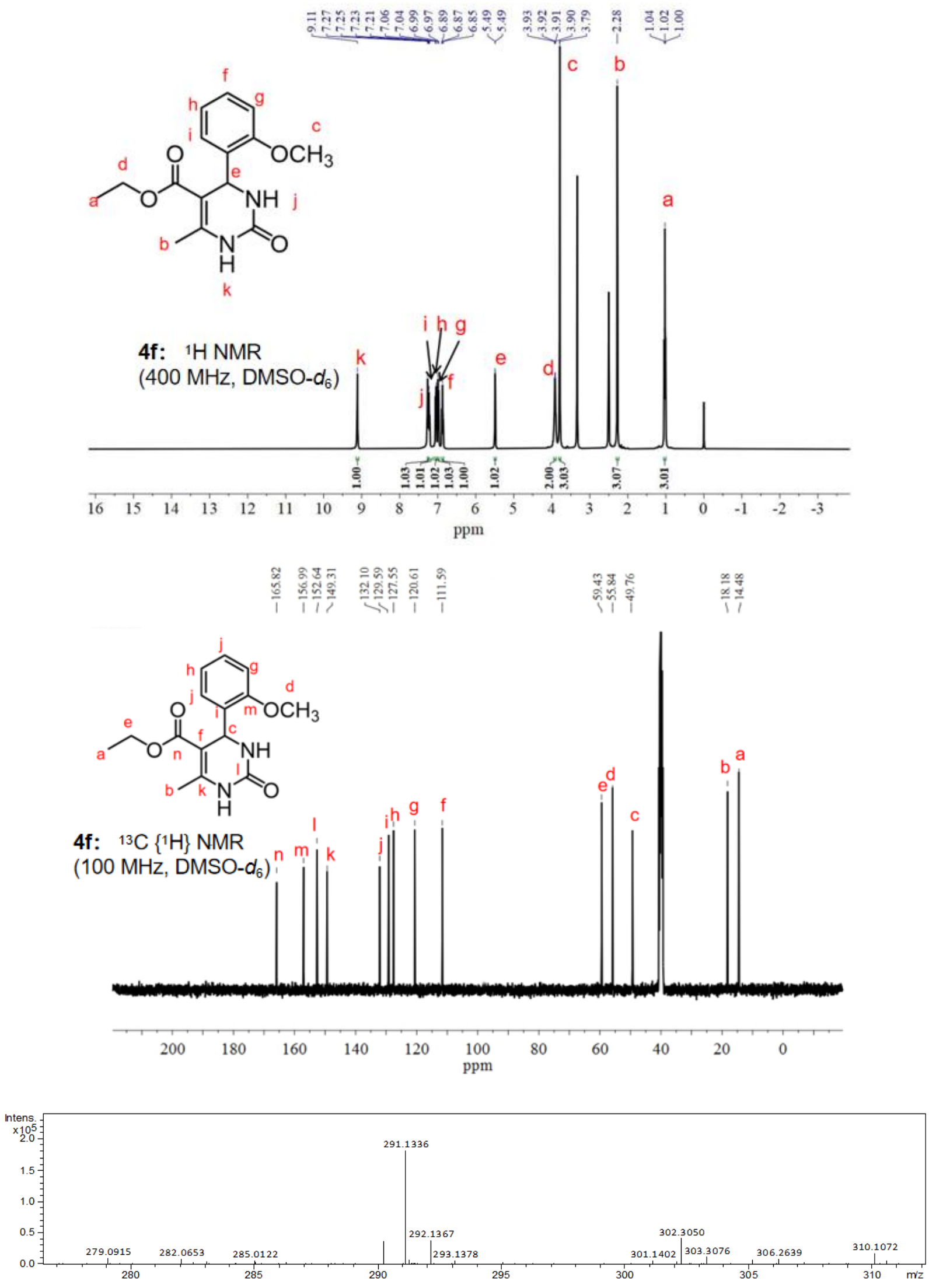

Figure S17. ${ }^{1 \mathrm{H}}$ and ${ }^{13} \mathrm{C}$ NMR, and MS spectra for 5-(ethoxycarbonyl)-6-methyl-4-(2-methoxyphenyl)-3,4dihydropyrimidin-2(1H)-one (Table 1 , entry $6, \mathbf{4 f}$ ). 
<smiles>[Z]COC(=O)C1=C([2H])NC(=O)N[C@H]1c1ccc(OC)cc1</smiles>

4g: $1 \mathrm{H}$ NMR (400 MHz, DMSO- $d_{6}$ )
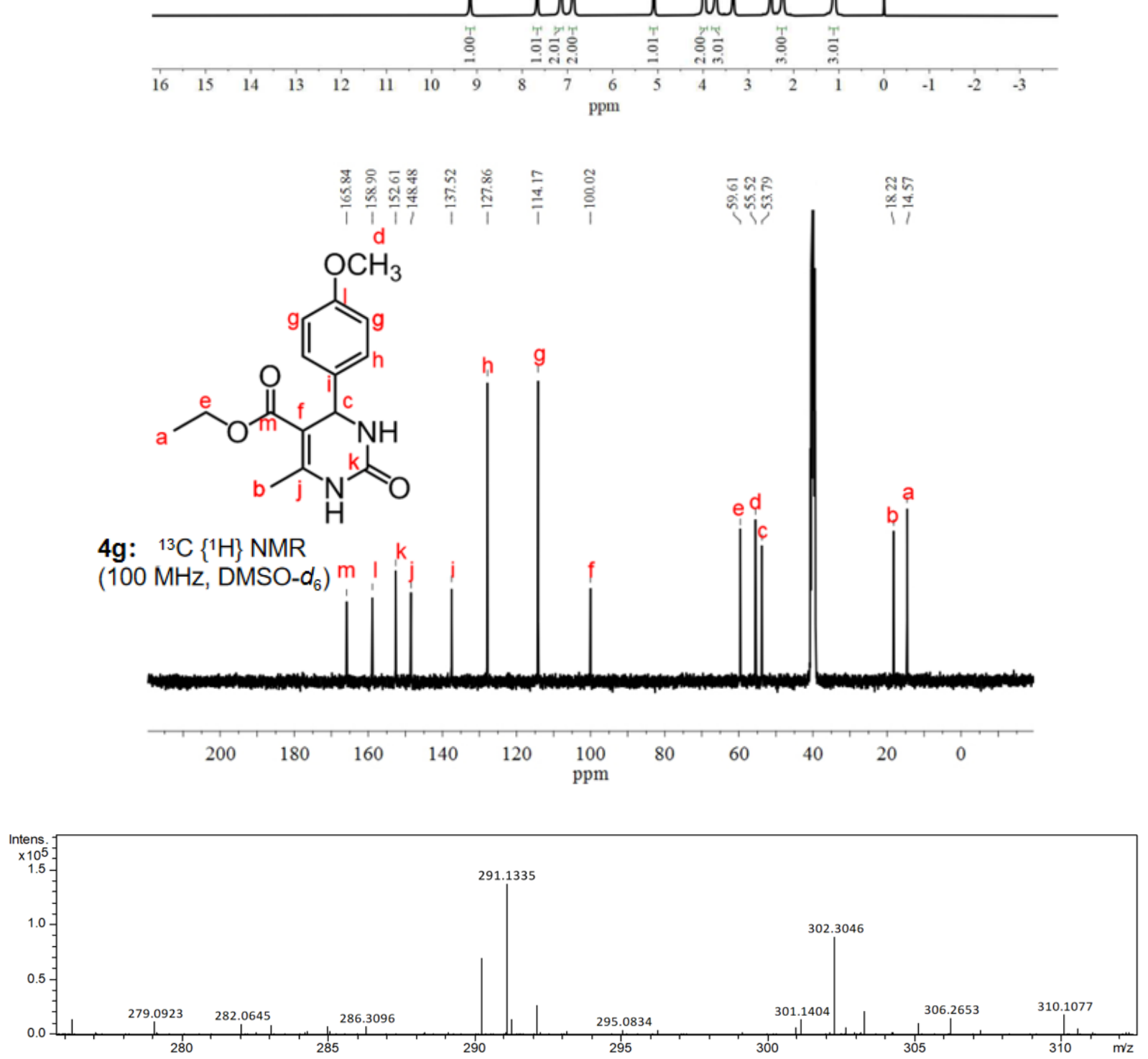

Figure S18. ${ }^{1} \mathrm{H}$ and ${ }^{13} \mathrm{C}$ NMR, and MS spectra for 5-(ethoxycarbonyl)-6-methyl-4-(4-methoxyphenyl)-3,4dihydropyrimidin-2(1H)-one (Table 1, entry 7, 4g). 
<smiles>CCOC(=O)C1=C(C)NC(=O)NC1c1ccc(O)cc1</smiles>

4h: 1H NMR $\left(400 \mathrm{MHz}, \mathrm{DMSO}-d_{6}\right)$
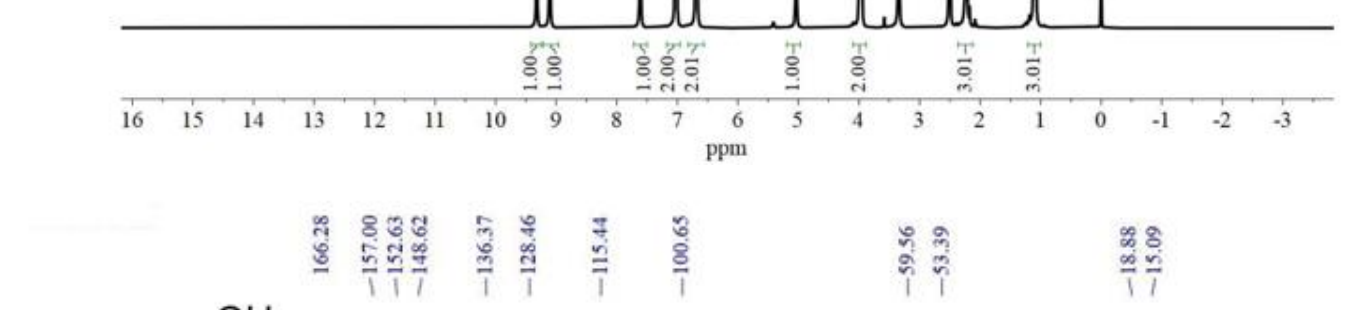<smiles>CCOC(=O)C1=C(C)NC(=O)NC1c1ccc(O)cc1</smiles>

4h: ${ }^{13} \mathrm{C}\left\{{ }^{1} \mathrm{H}\right\}$ NMR $\left(100 \mathrm{MHz}, \mathrm{DMSO}-d_{6}\right)$

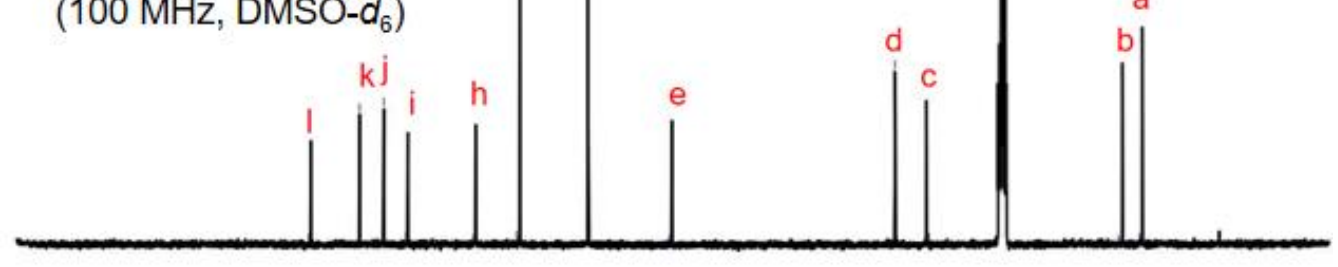

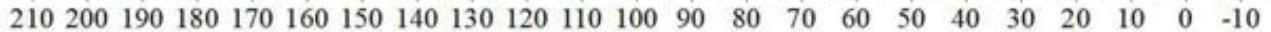
$\mathrm{ppm}$

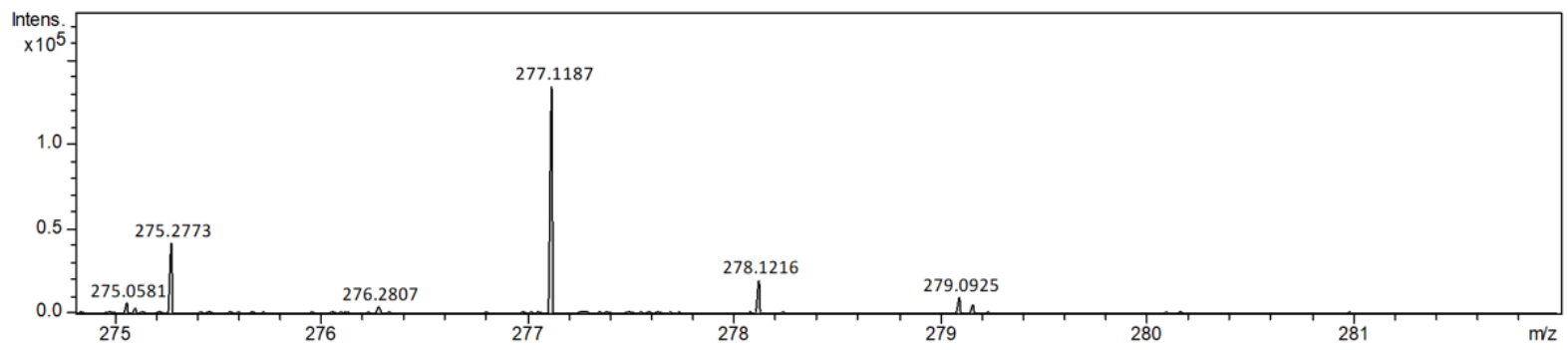

Figure S19. ${ }^{1} \mathrm{H}$ and ${ }^{13} \mathrm{C} N M R$, and $\mathrm{MS}$ spectra for 5-(ethoxycarbonyl)-6-methyl-4-(4-hydroxyphenyl)-3,4dihydropyrimidin-2(1H)-one (Table 1 , entry $8, \mathbf{4 h}$ ). 

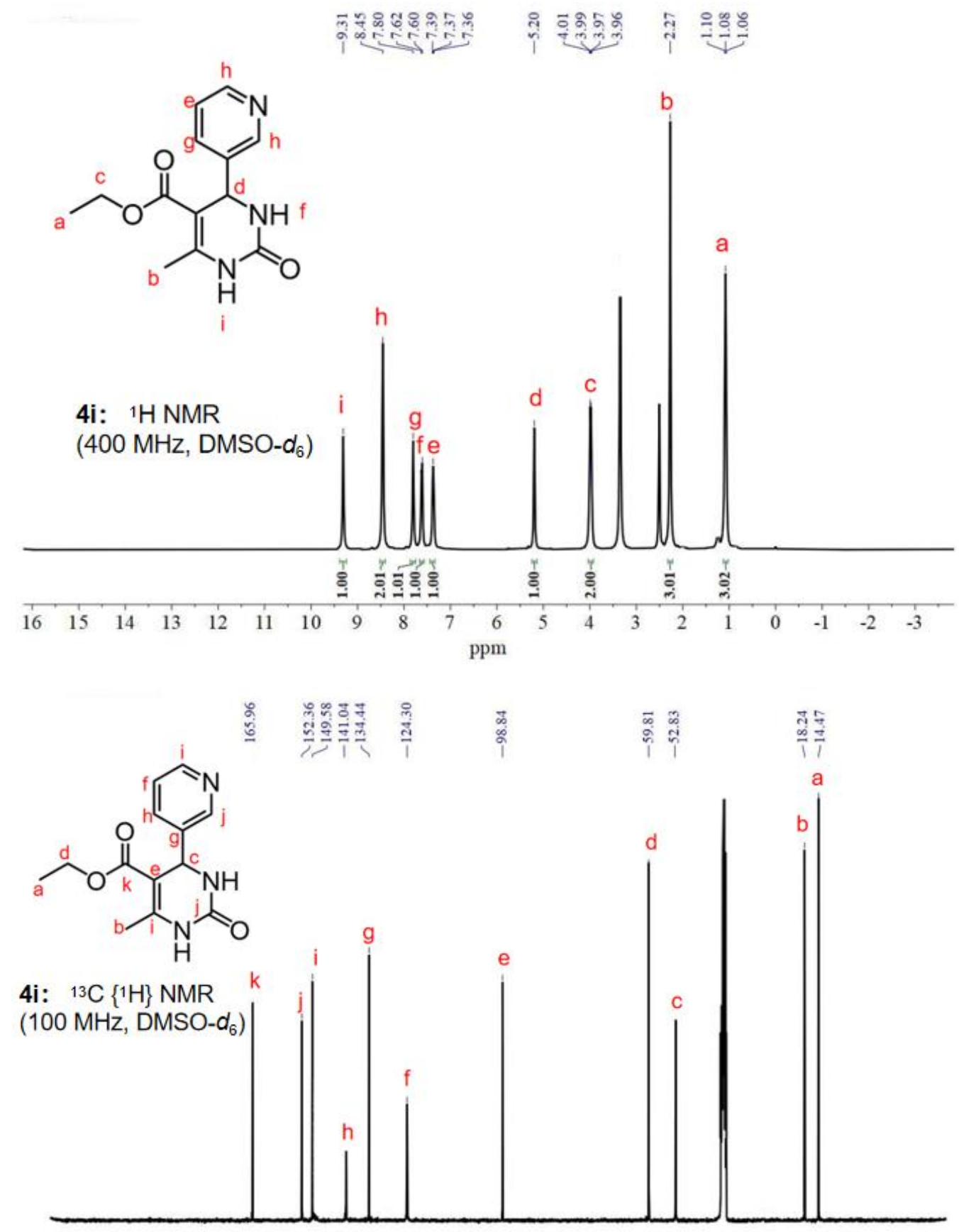

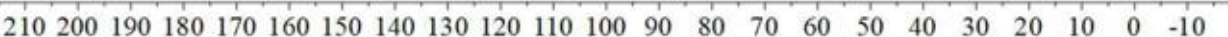
ppm

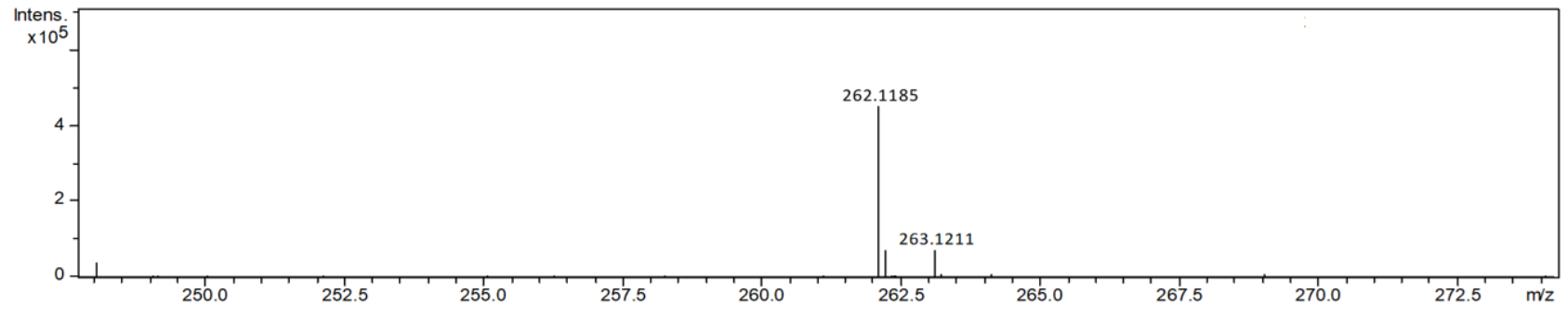

Figure S20. ${ }^{1} \mathrm{H}$ and ${ }^{13} \mathrm{C} \mathrm{NMR}$, and MS spectra for 5-(ethoxycarbonyl)-6-methyl-4-(3-pyridine)-3,4-dihydropyrimi din-2(1H)-one (Table 1, entry 9, 4i). 

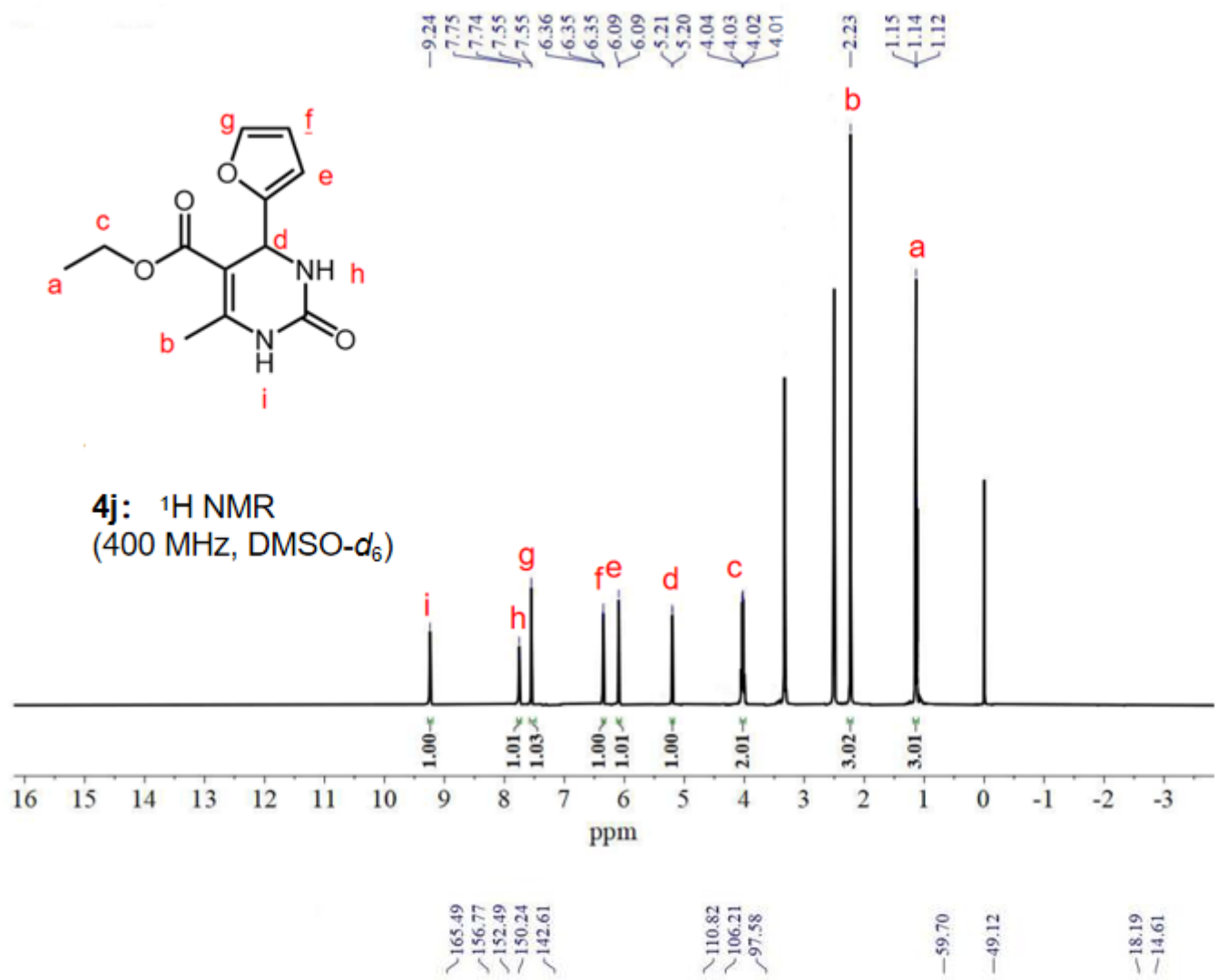<smiles>CCOC(=O)C1=C(C)NC(=O)NC1c1ccco1</smiles>

4j: ${ }^{13} \mathrm{C}\{1 \mathrm{H}\} \mathrm{NMR}$ $\left(100 \mathrm{MHz}, \mathrm{DMSO}-d_{6}\right)$

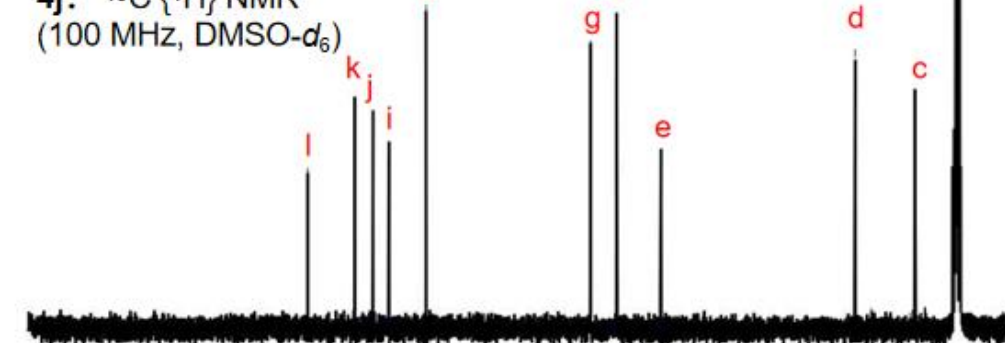

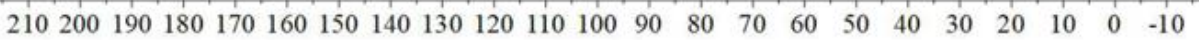
ppm

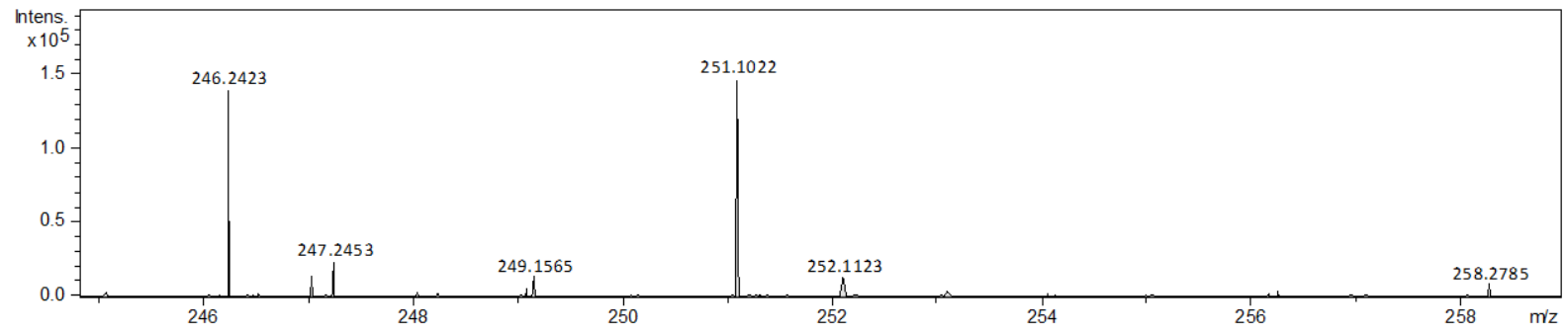

Figure S21. ${ }^{1} \mathrm{H}$ and ${ }^{13} \mathrm{C}$ NMR, and MS spectra for 5-(ethoxycarbonyl)-6-methyl-4-(2-furaldehyde)-3,4dihydropyrimidin-2(1H)-one (Table 1, entry10, 4j). 


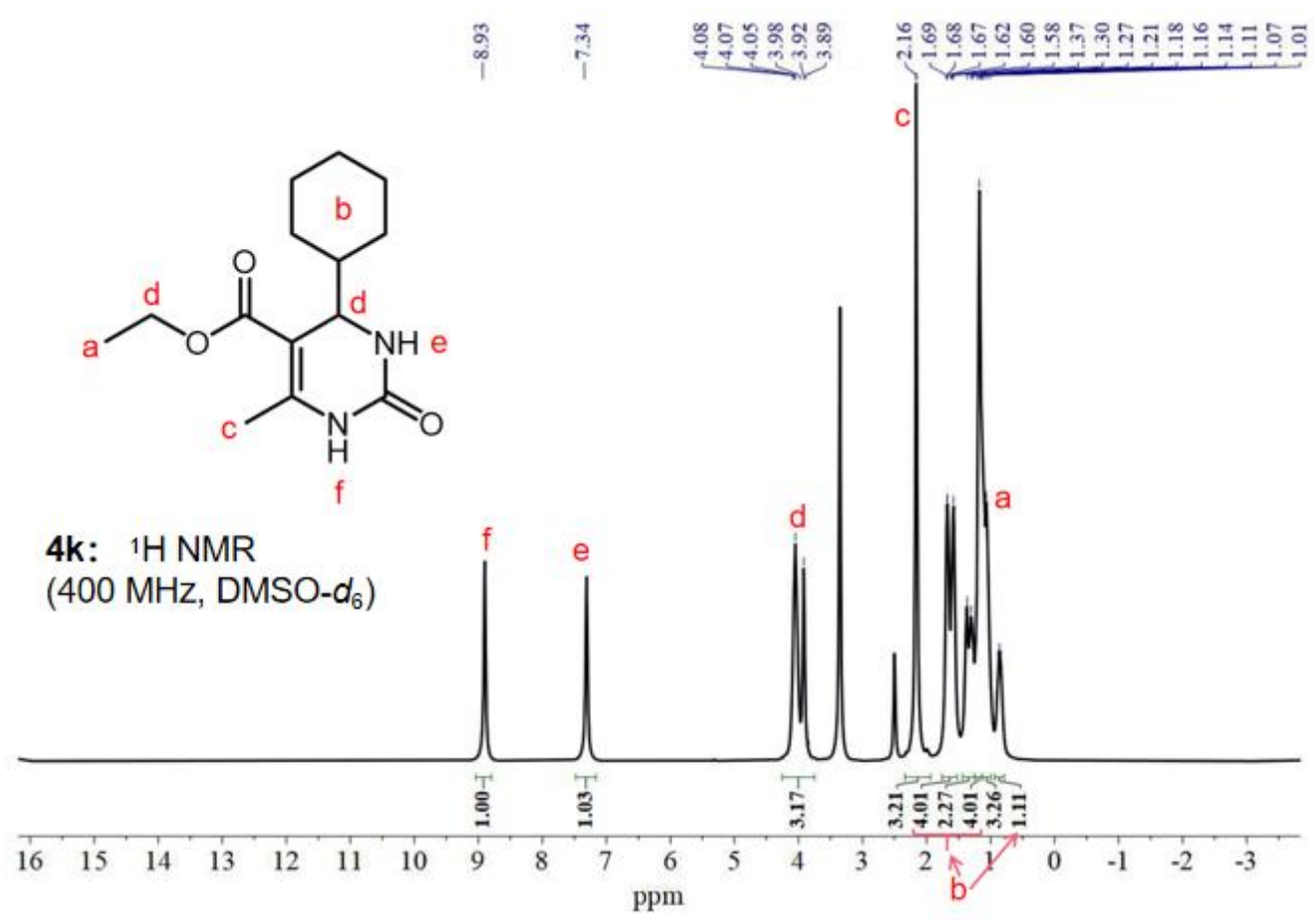

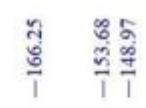

के

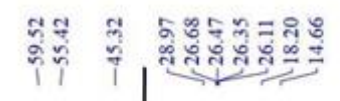<smiles>CC1=C(C(=O)OC(C)C)C(C2CCCCC2)NC(=O)N1</smiles>

4k: ${ }^{13} \mathrm{C}\left\{{ }^{1} \mathrm{H}\right\}$ NMR $\left(100 \mathrm{MHz}, \mathrm{DMSO}-d_{6}\right)$

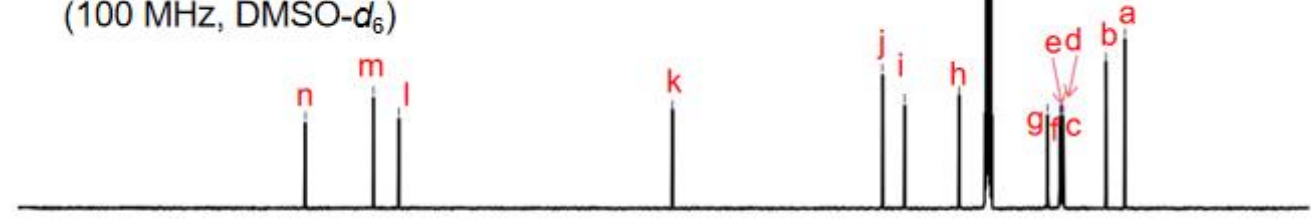

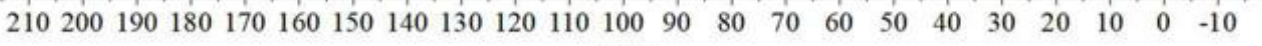
ppm

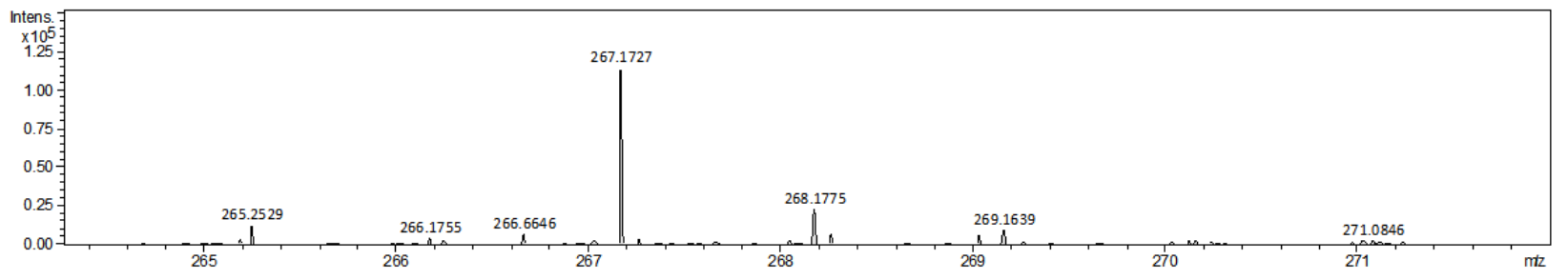

Figure S22. ${ }^{1} \mathrm{H}$ and ${ }^{13} \mathrm{C}$ NMR, and MS spectra for 5-(ethoxycarbonyl)-6-methyl-4-Cyclohexyl-3,4-dihydropyri midin-2(1H)-one (Table 1, entry 11, 4k). 
<smiles>[3H]C[13CH2]CCC1NC(=O)NC(C)=C1C(=O)OC[CH]</smiles>

4I: ${ }^{1} \mathrm{H}$ NMR $\left(400 \mathrm{MHz}, \mathrm{DMSO}-\mathrm{d}_{6}\right)$
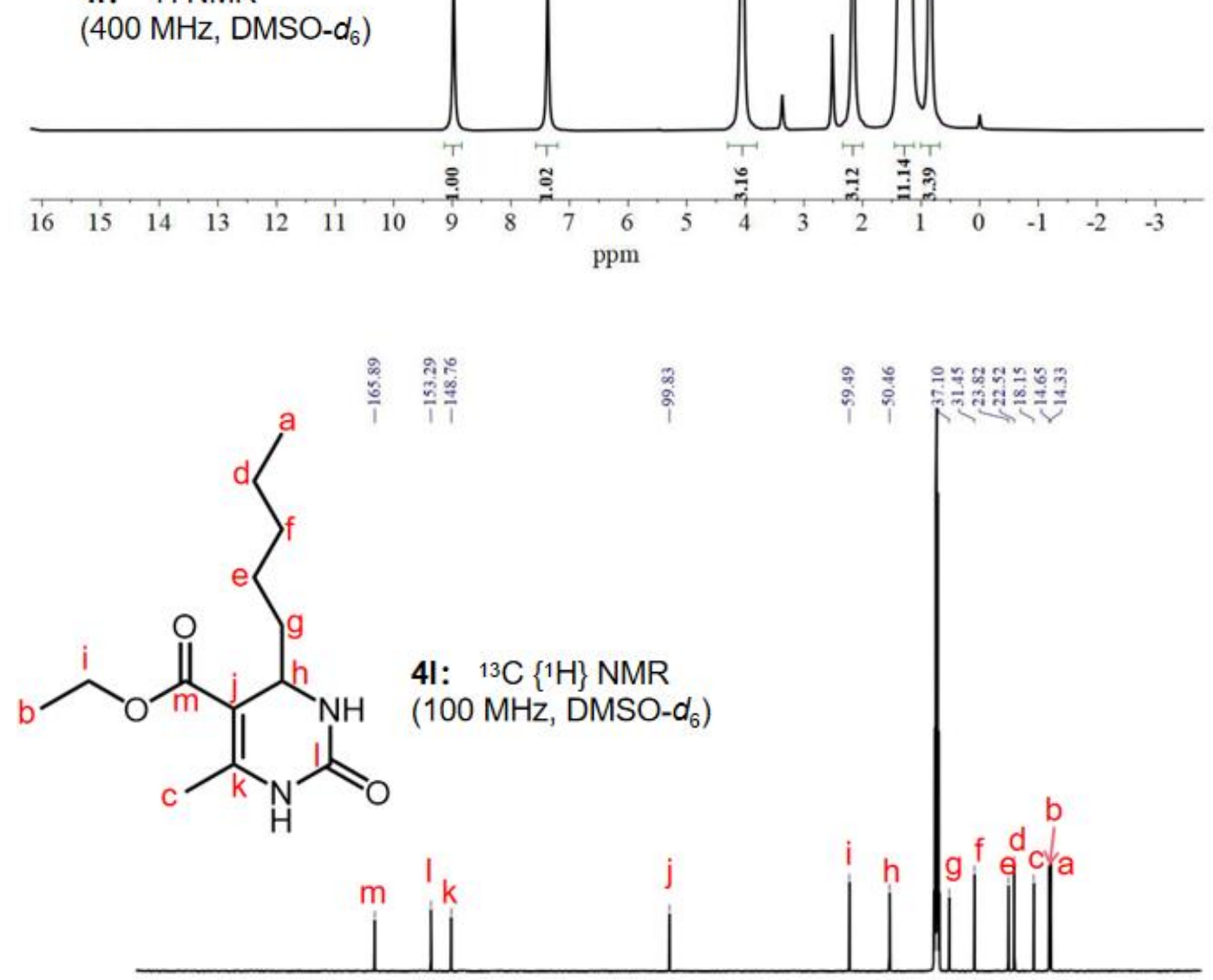

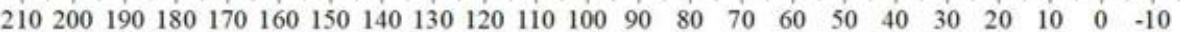
ppm

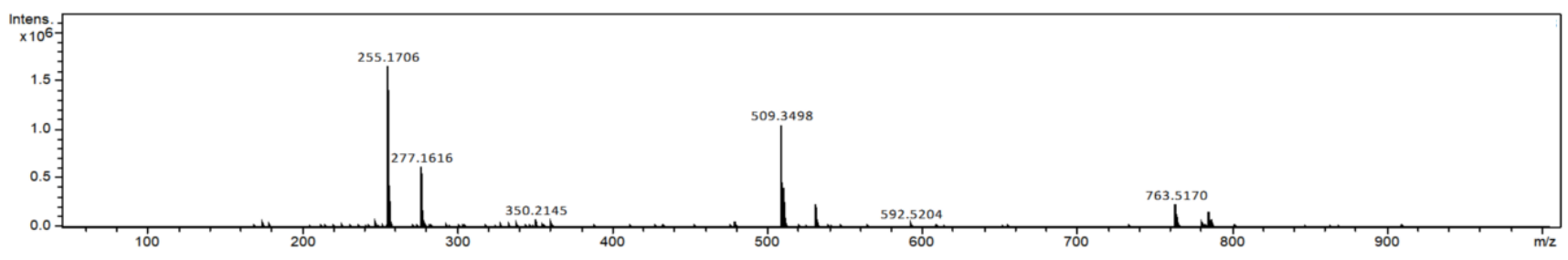

Figure S23. ${ }^{1} \mathrm{H}$ and ${ }^{13} \mathrm{C}$ NMR, and MS spectra for 5-(ethoxycarbonyl)-6-methyl-4-Hexyl-3,4-dihydropyrimidin 2(1H)-one (Table 1, entry 12, 4I). 

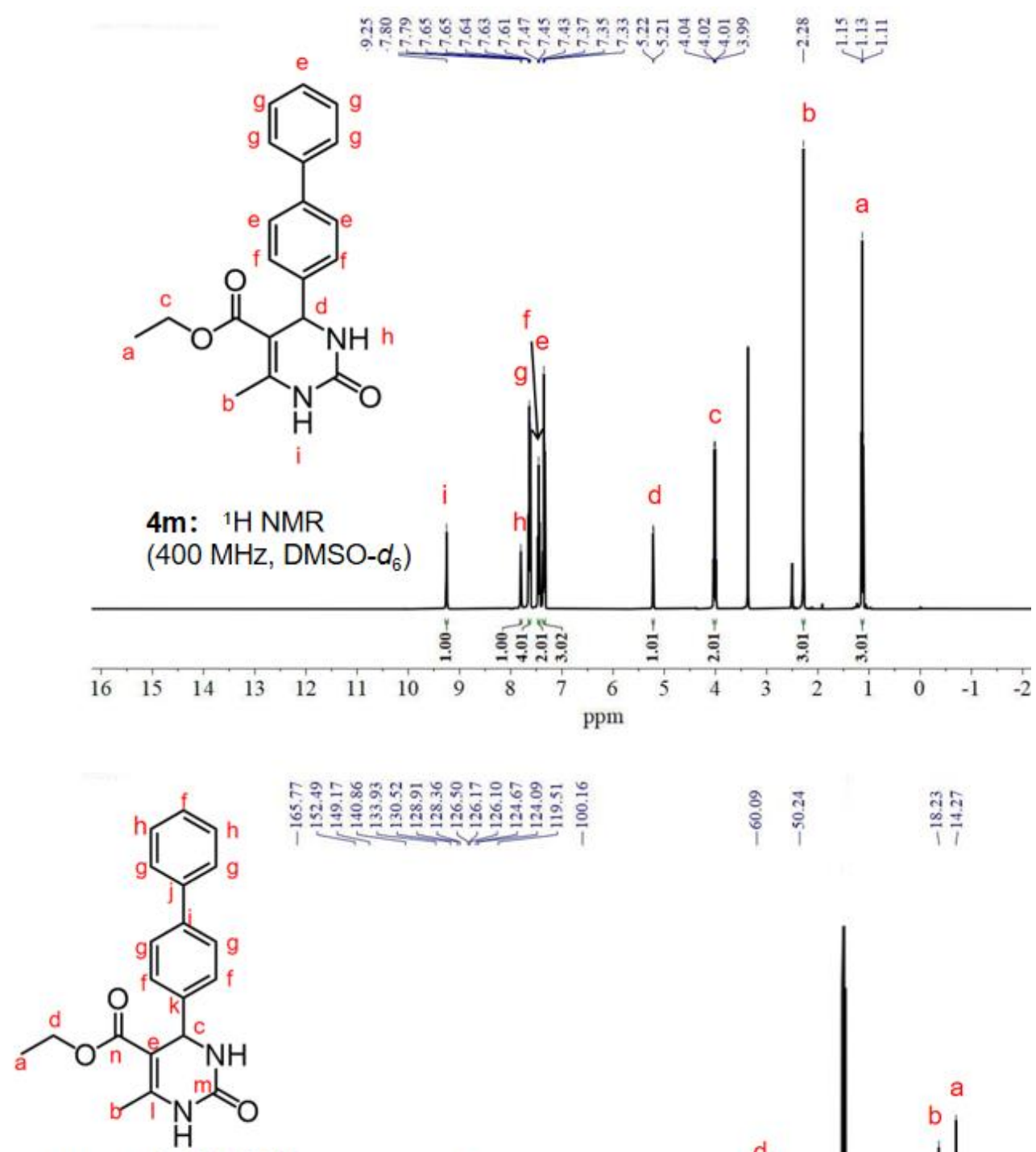

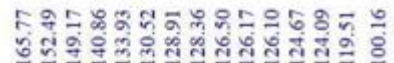

1

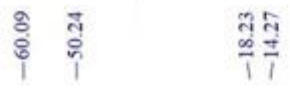

4m: ${ }^{13} \mathrm{C}\left\{{ }^{1} \mathrm{H}\right\}$ NMR $\left(100 \mathrm{MHz}, \mathrm{DMSO}-d_{6}\right)$

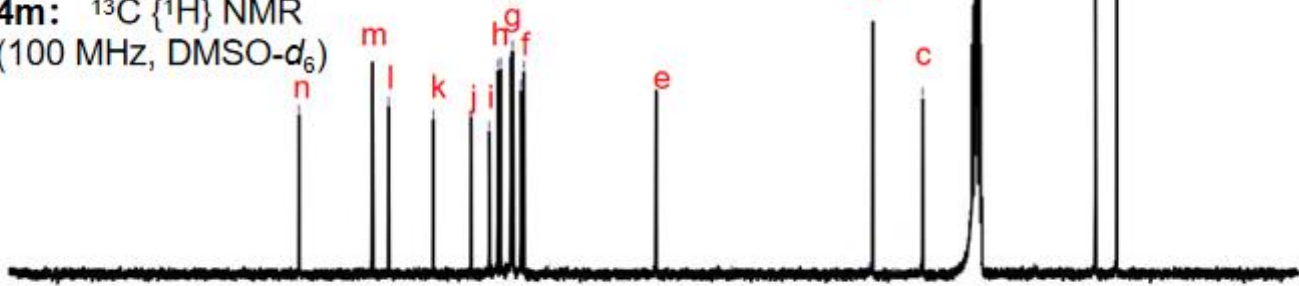

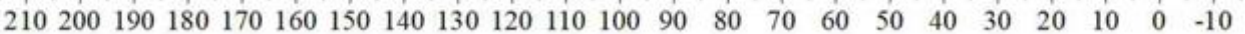
ppm

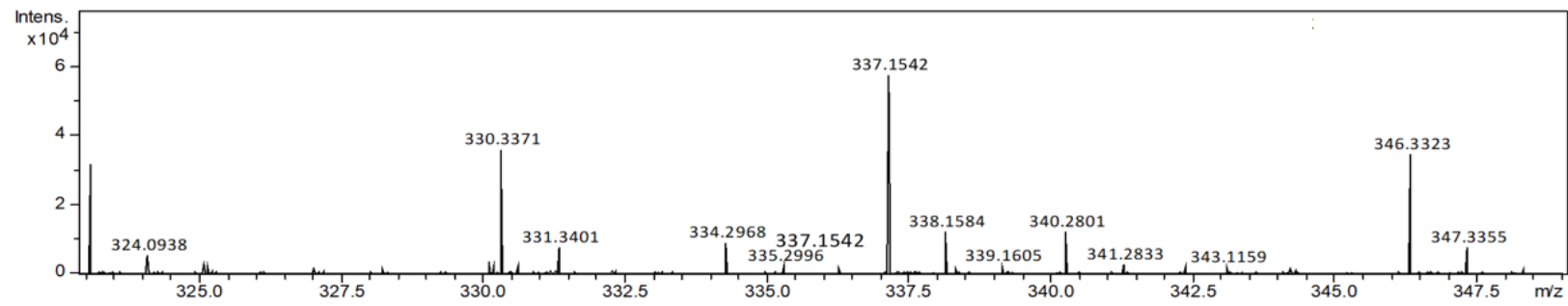

Figure S24. ${ }^{1} \mathrm{H}$ and ${ }^{13} \mathrm{C}$ NMR, and MS spectra for 5-(ethoxycarbonyl)-6-methyl-4-(4-biphenylyl)-3,4dihydropyrimidin-2(1H)-one (Table 1 , entry $13,4 \mathrm{~m}$ ). 
<smiles>CCOC(=O)C1=C(C)NC(=O)NC1c1cccc2ccccc12</smiles>

b

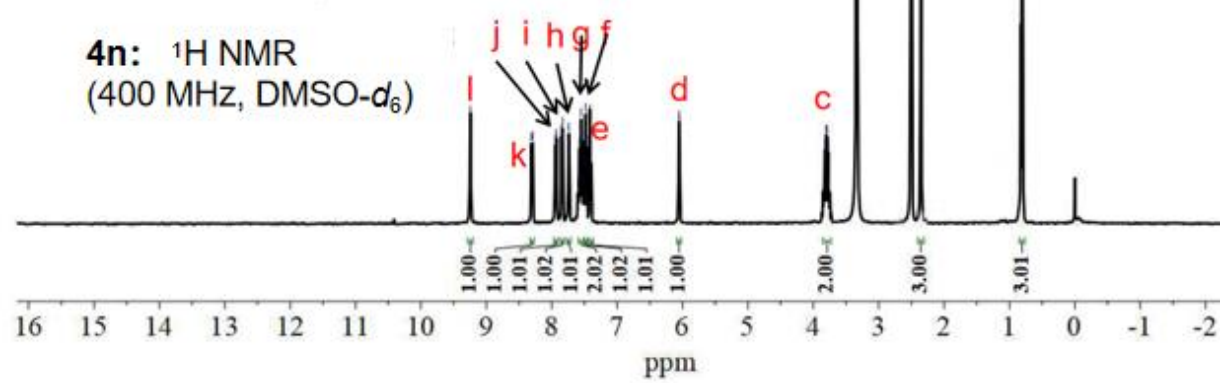

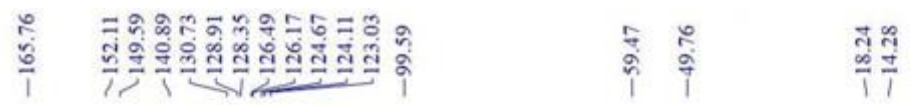<smiles>CCOC(=O)C1=C(C)NC(=O)NC1c1cccc2ccccc12</smiles>

4n: ${ }^{13} \mathrm{C}\left\{{ }^{1} \mathrm{H}\right\}$ NMR $\left(100 \mathrm{MHz}, \mathrm{DMSO}-d_{6}\right)$

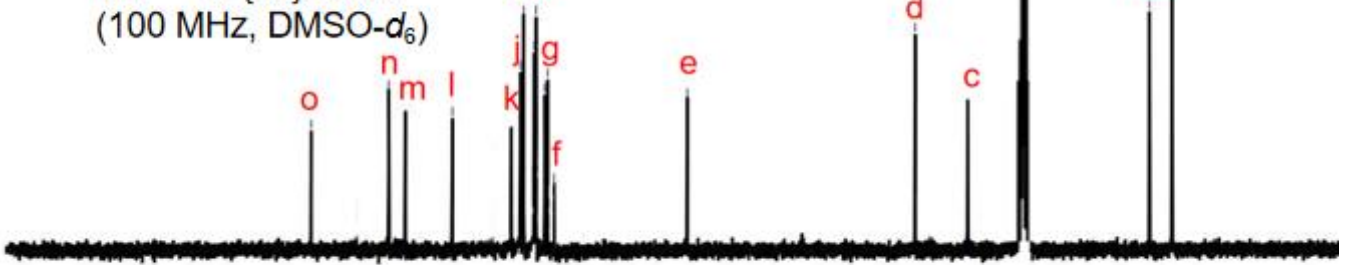

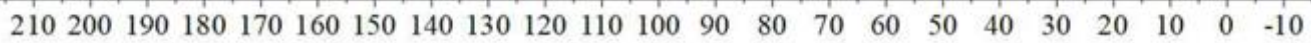
ppm

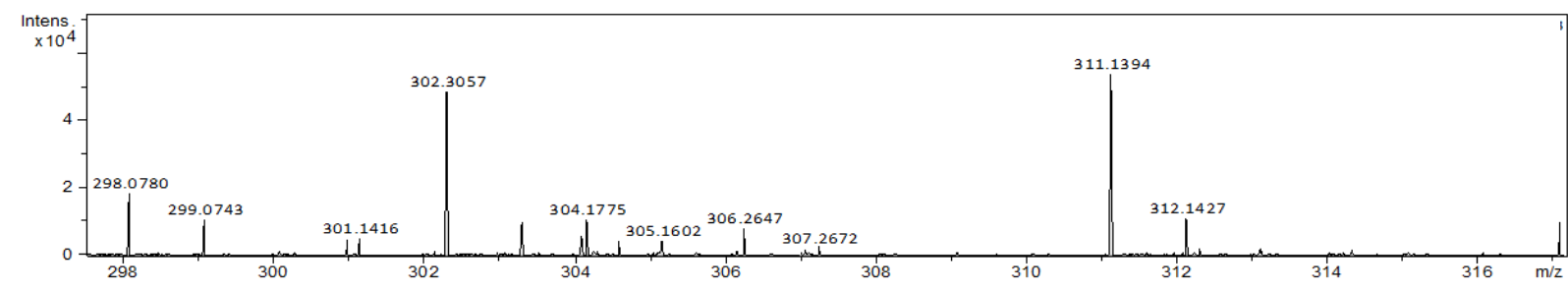

Figure S25. ${ }^{1} \mathrm{H}$ and ${ }^{13} \mathrm{C}$ NMR, and MS spectra for 5-(ethoxycarbonyl)-6-methyl-4-(2-Naphthyl)-3,4dihydropyrimidin-2(1H)-one (Table 1 , entry $14,4 \mathrm{n}$ ). 

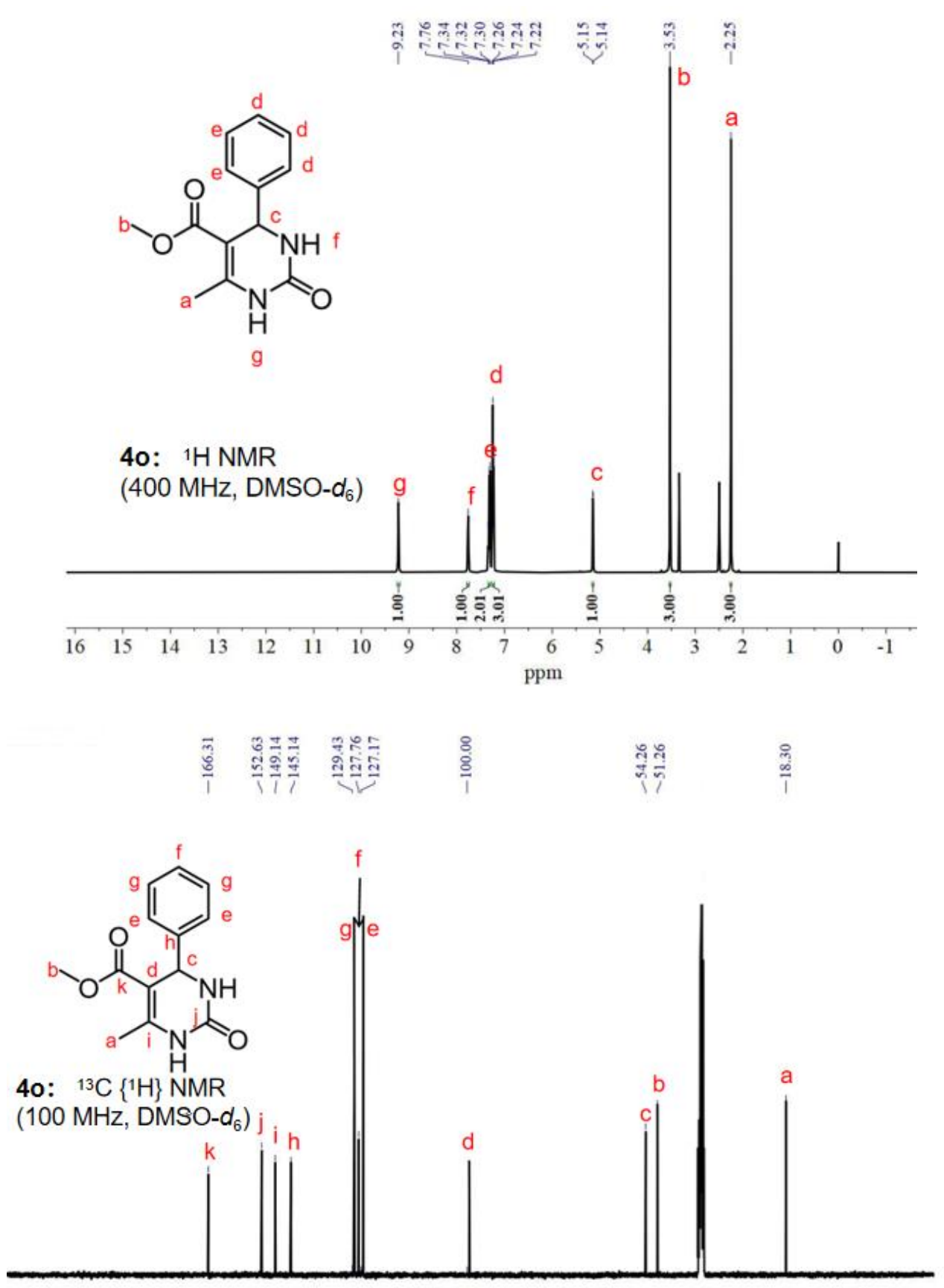

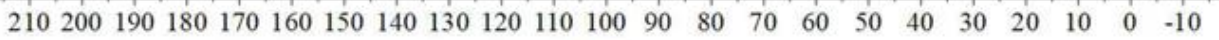
ppm

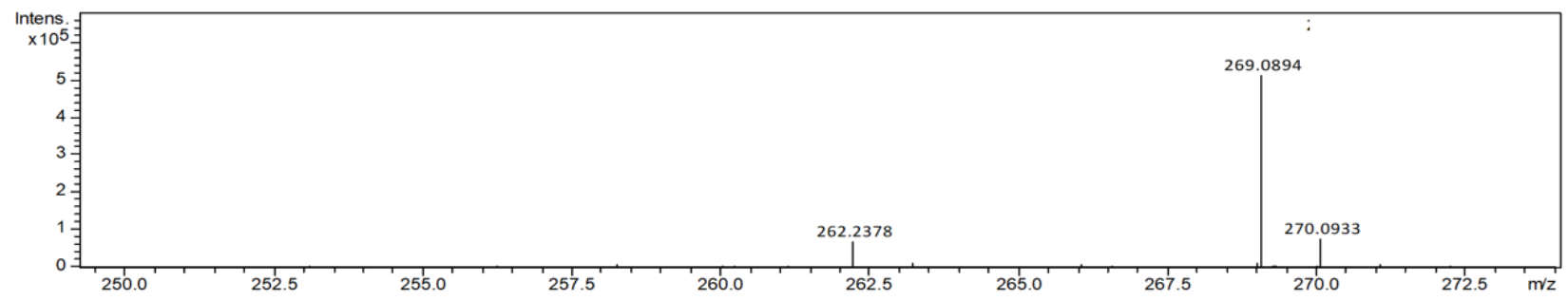

Figure S26. ${ }^{1} \mathrm{H}$ and ${ }^{13} \mathrm{C} \mathrm{NMR}$, and MS spectra for 5-(methoxycarbonyl)-6-methyl-4-phenyl-3,4-dihydropyrimidin2(1H)-one (Table 1, entry 15, 4o). 


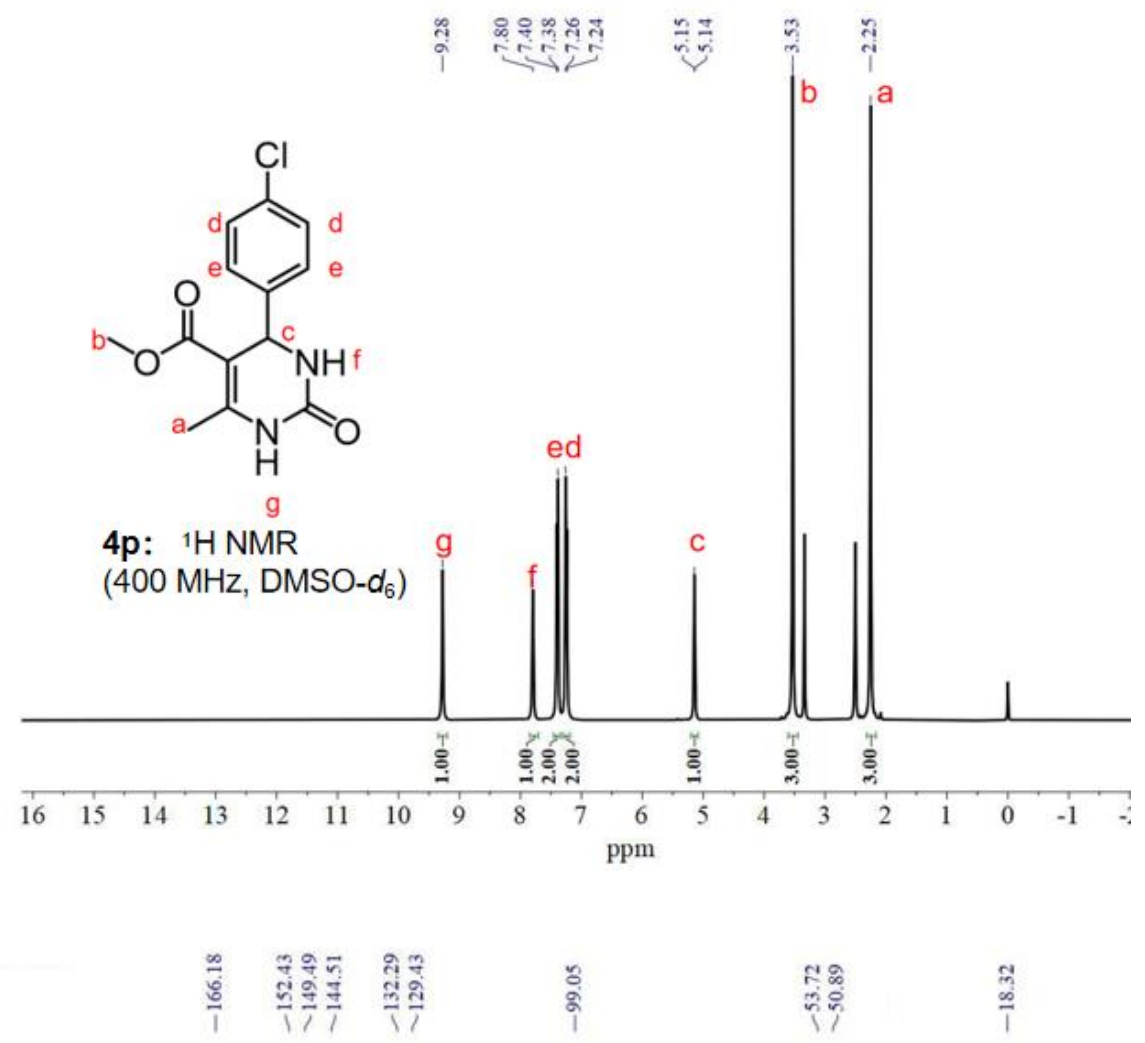<smiles>COC(=O)C1=C(C)NC(=O)NC1c1ccc(Cl)cc1</smiles>

4p: ${ }^{13} \mathrm{C}\left\{{ }^{1} \mathrm{H}\right\}$ NMR

$\left(100 \mathrm{MHz}, \mathrm{DMSO}-\mathrm{d}_{6}\right)$ i
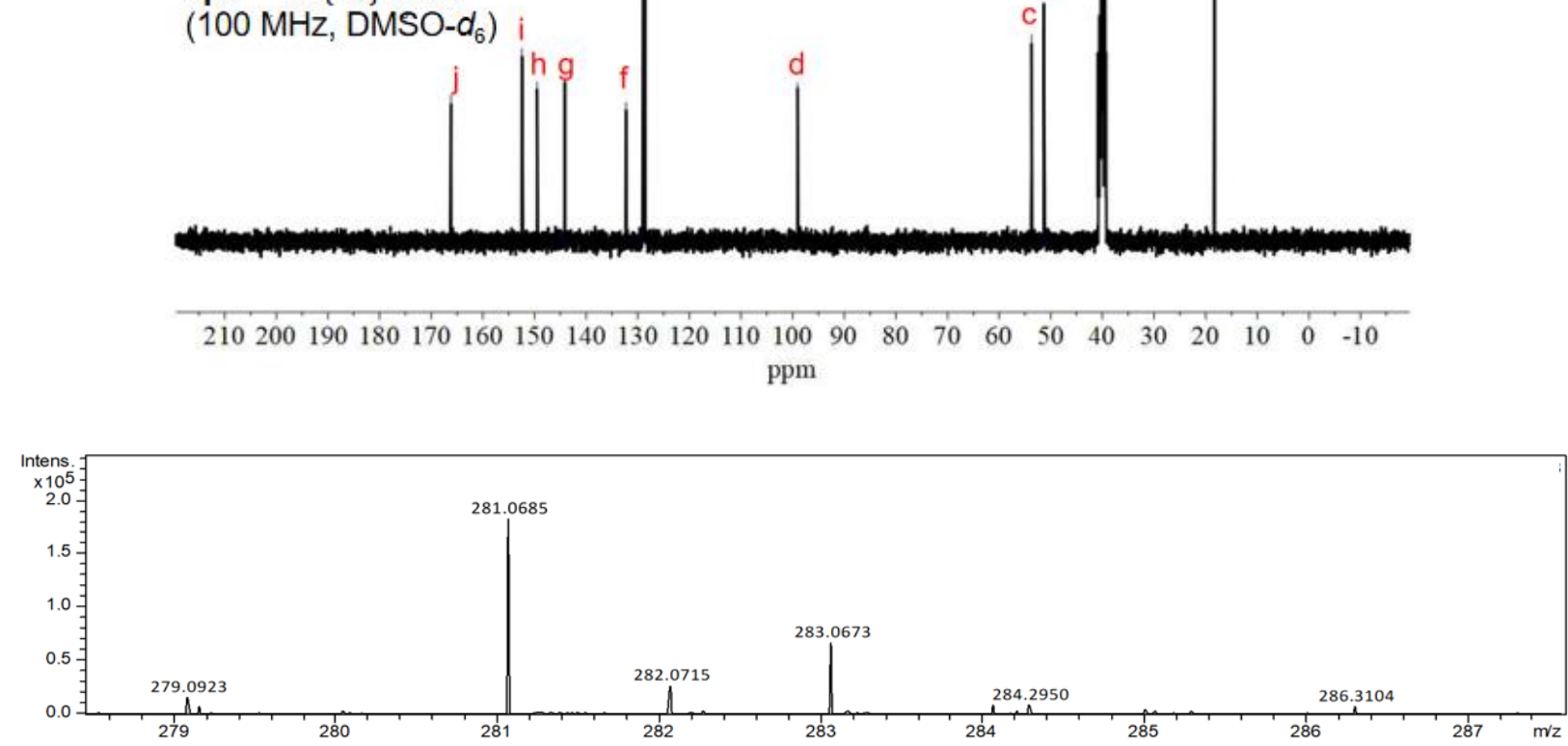

Figure S27. ${ }^{1} \mathrm{H}$ and ${ }^{13} \mathrm{C} \mathrm{NMR}$, and MS spectra for 5-(methoxycarbonyl)-6-methyl-4-(4-chlorophenyl)-3,4dihydropyrimidin-2(1H)-one (Table 1, entry 16, 4p). 


$$
\text { ते }
$$<smiles>COC(=O)C1=C(C)NC(=O)NC1c1ccc(C)cc1</smiles>

4q: 1 H NMR $\left(400 \mathrm{MHz}, \mathrm{DMSO}-\mathrm{d}_{6}\right)$
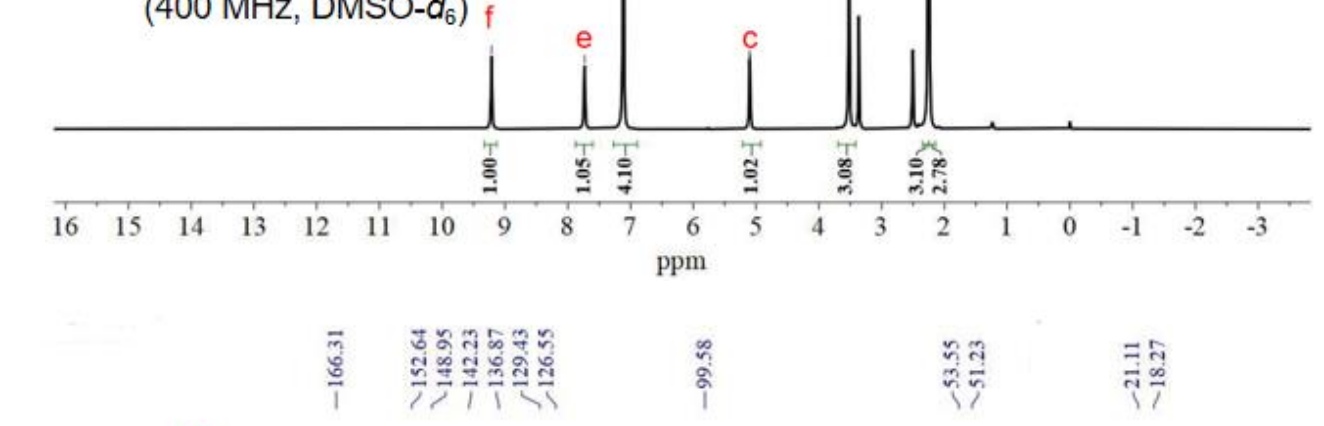<smiles>COC(=O)C1=C(C)NC(=O)NC1c1ccc(C)cc1</smiles>

4q: ${ }^{13} \mathrm{C}\left\{{ }^{1} \mathrm{H}\right\}$ NMR

$\left(100 \mathrm{MHz}, \mathrm{DMSO}-d_{6}\right)$

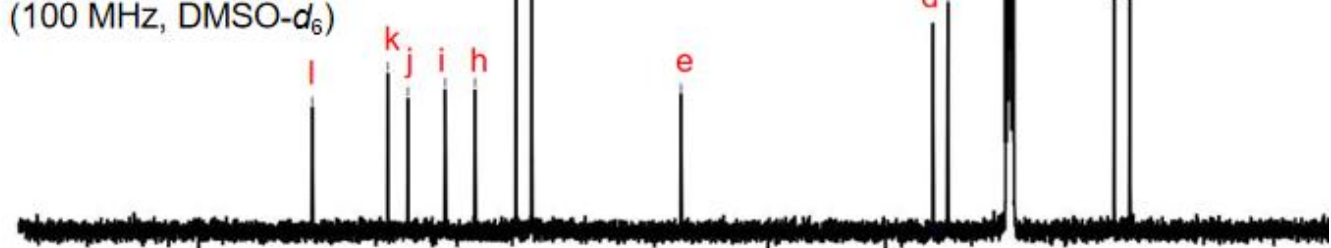

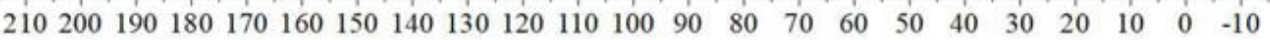
$\mathrm{ppm}$

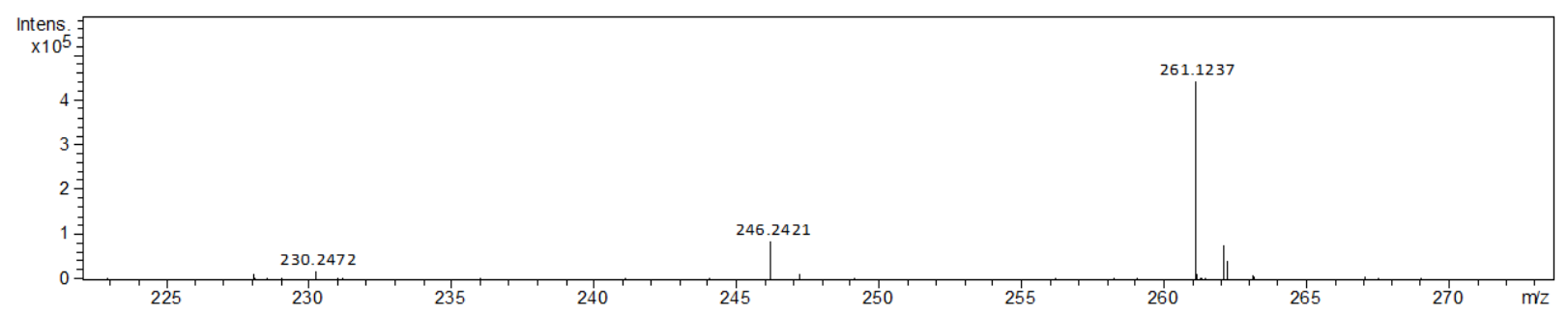

Figure S28. ${ }^{1 \mathrm{H}}$ and ${ }^{13} \mathrm{C}$ NMR, and MS spectra for 5-(methoxycarbonyl)-6-methyl-4-(4-methylphenyl)-3,4dihydropyrimidin-2(1H)-one (Table 1, entry 17, 4q). 

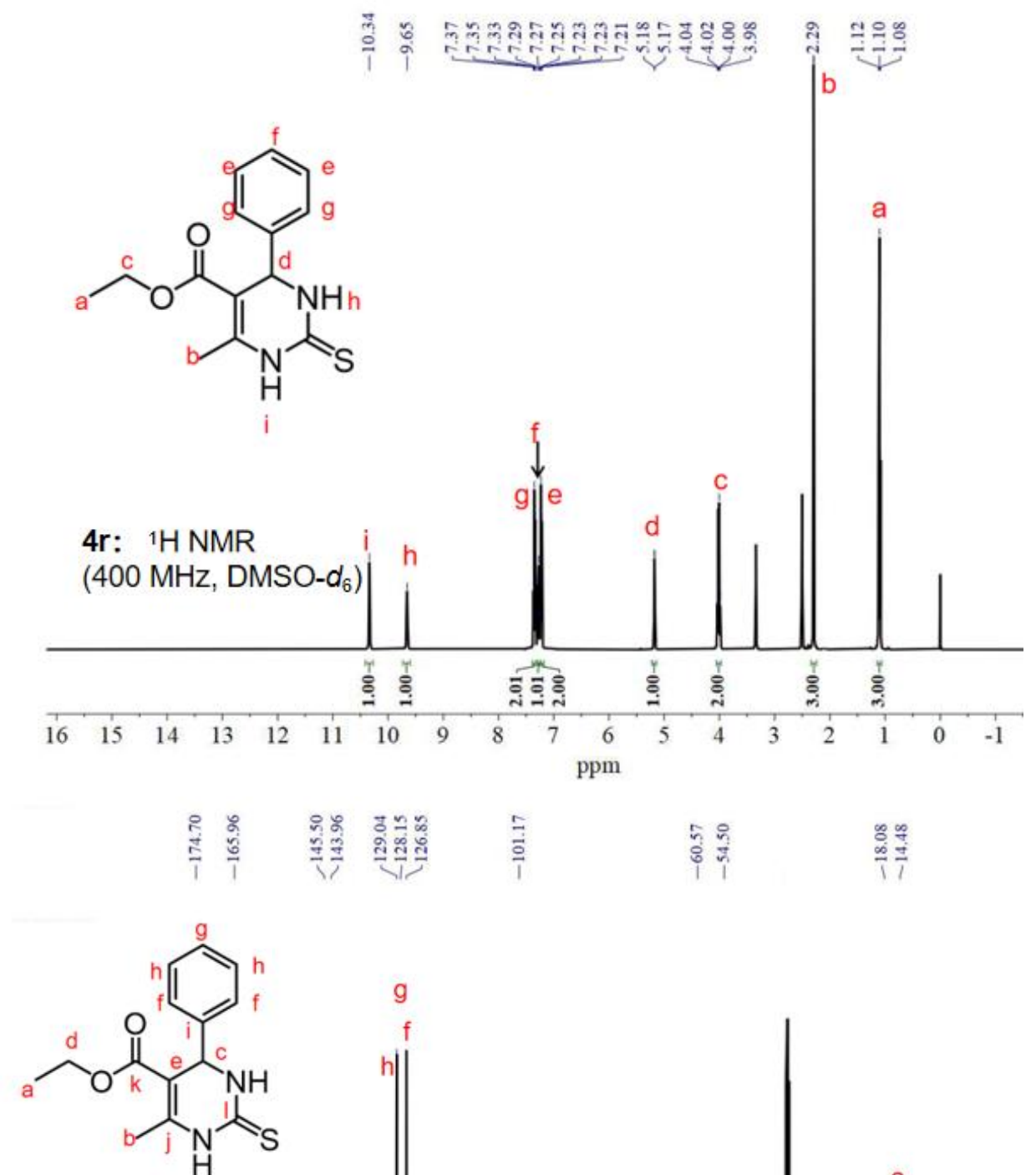

4r: ${ }^{13} \mathrm{C}\left\{{ }^{1} \mathrm{H}\right\}$ NMR

(100 MHz, DMSO- $d_{6}$ )

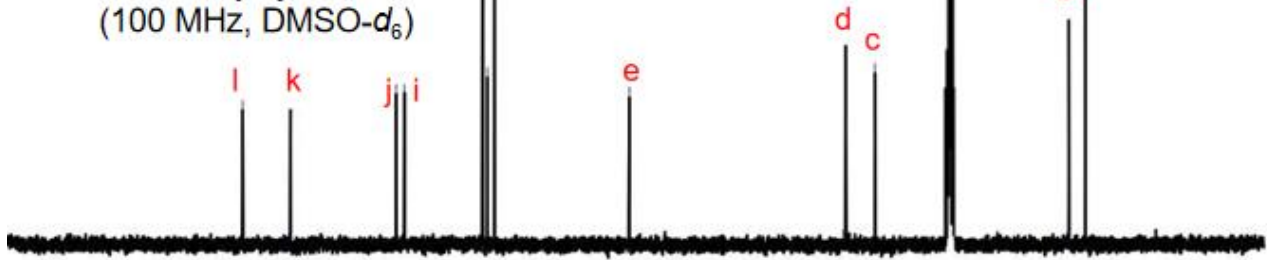

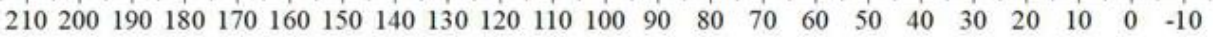
ppm

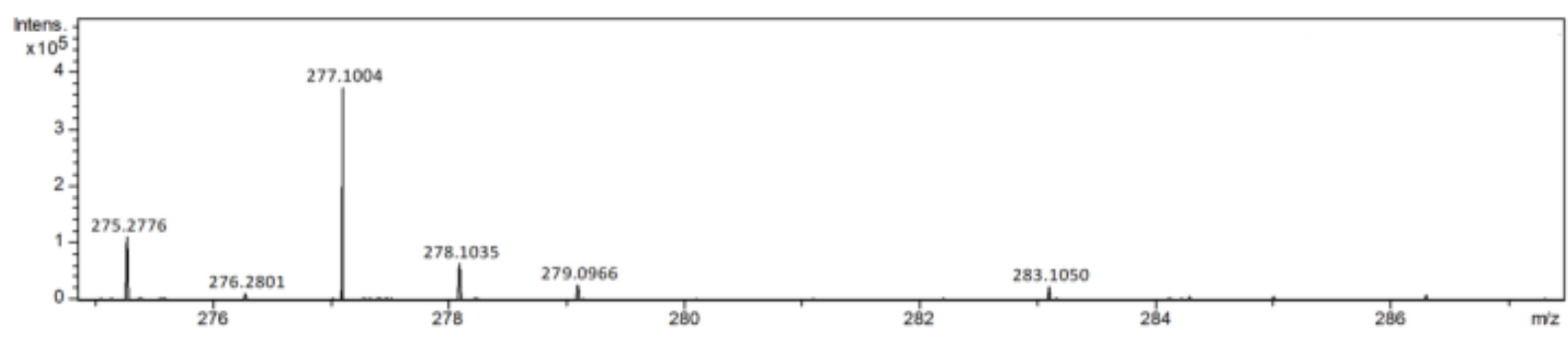

Figure S29. ${ }^{1} \mathrm{H}$ and ${ }^{13} \mathrm{C} \mathrm{NMR}$, and MS spectra for 5-(ethoxycarbonyl)-6-methyl-4-phenyl-3,4-dihydropyrimidin2(1H)-thione (Table 1, entry 18, 4r). 


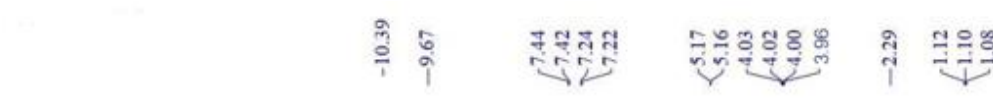<smiles>CCOC(=O)C1=C(C)NC(=S)NC1c1ccc(Cl)cc1</smiles>
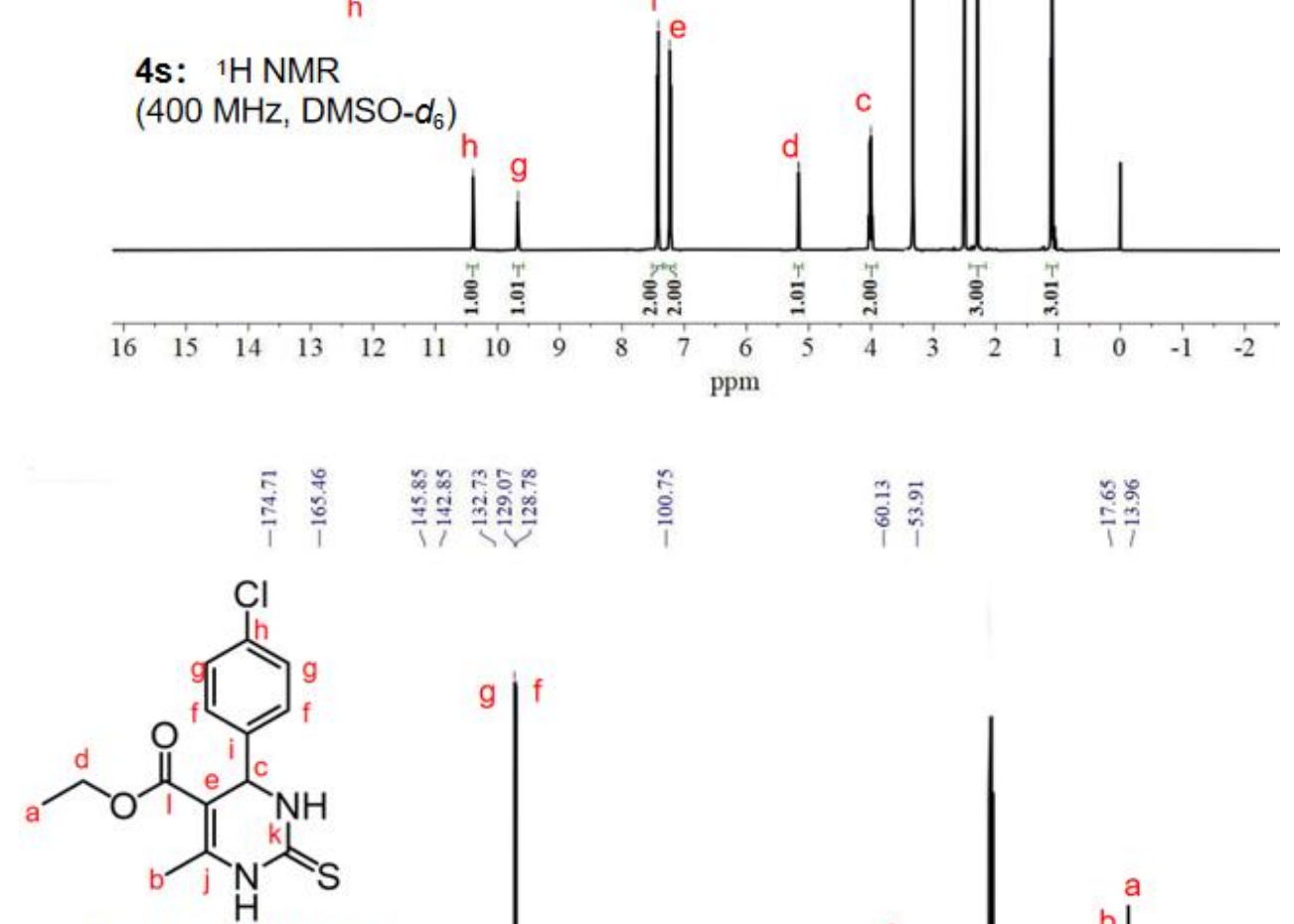

4s: ${ }^{13} \mathrm{C}\{1 \mathrm{H}\} \mathrm{NMR}$

$\left(100 \mathrm{MHz}, \mathrm{DMSO}-d_{6}\right)$

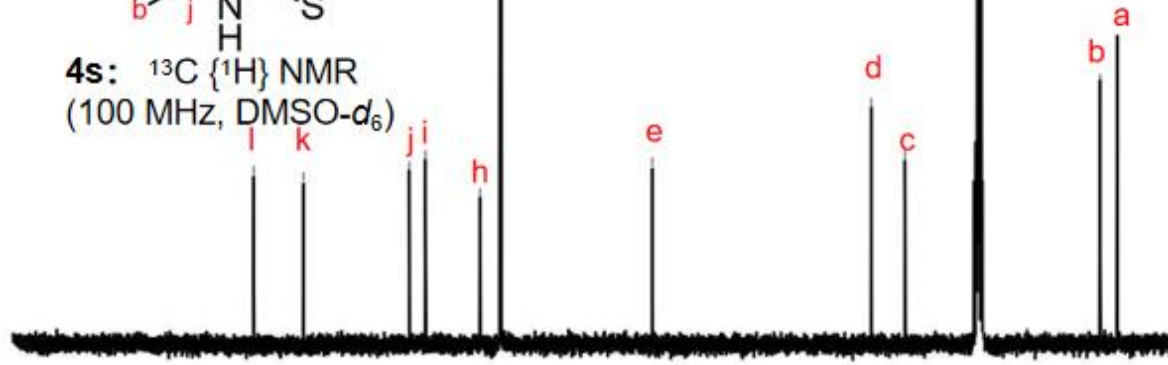

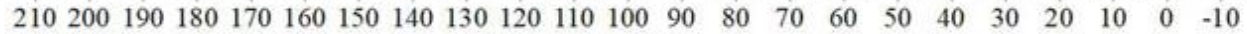

ppm

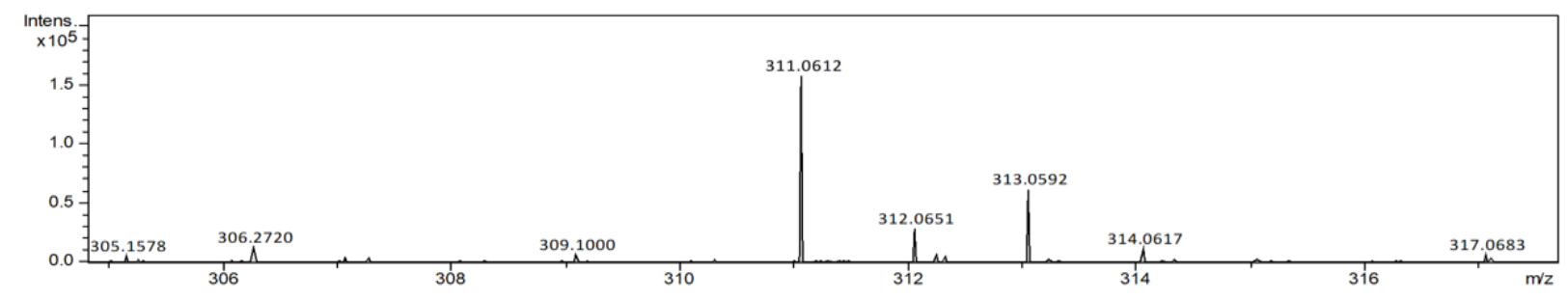

Figure S30. ${ }^{1} \mathrm{H}$ and ${ }^{13} \mathrm{C}$ NMR, and MS spectra for 5-(ethoxycarbonyl)-6-methyl-4-(4-chlorophenyl)-3,4dihydropyrimidin-2(1H)-thione (Table 1, entry 19, 4s). 

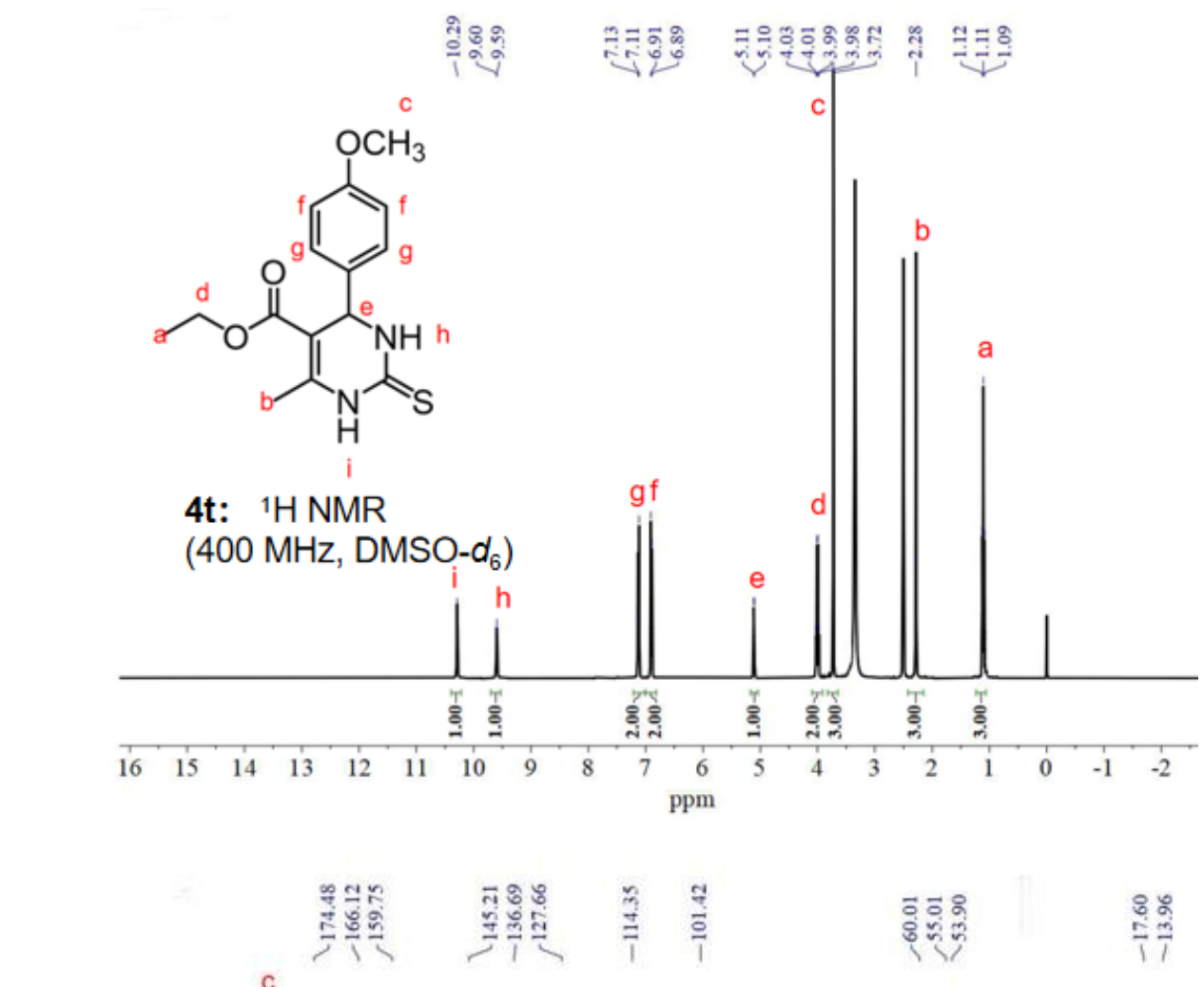<smiles>CCOC(=O)C1=C(C)NC(=S)NC1c1ccc(OC)cc1</smiles>

4t: ${ }^{13} \mathrm{C}\left\{{ }^{1} \mathrm{H}\right\} \mathrm{NMR}$ $\left(100 \mathrm{MHz}, \mathrm{DMSO}-d_{6}\right)$

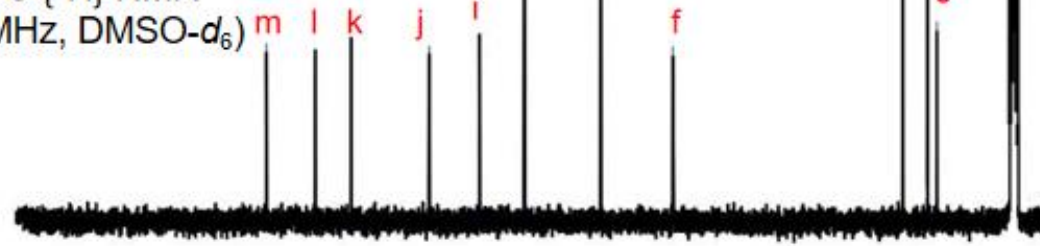

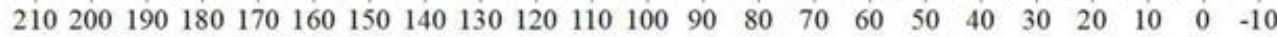
ppm

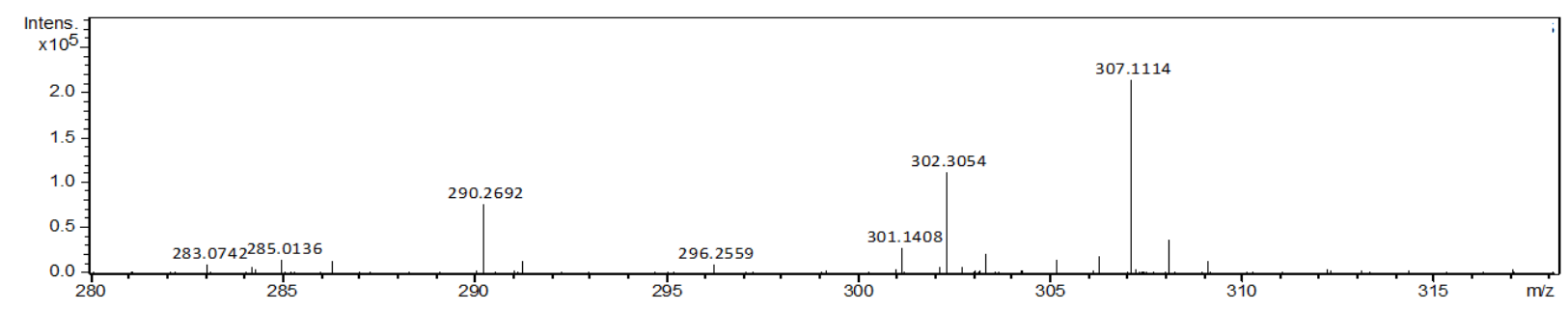

Figure S31. ${ }^{1 \mathrm{H}}$ and ${ }^{13} \mathrm{C}$ NMR, and MS spectra for 5-(ethoxycarbonyl)-6-methyl-4-(4-methoxyphenyl)-3,4dihydropyrimidin-2(1H)-thione (Table 1 , entry $20,4 \mathbf{t}$ ). 

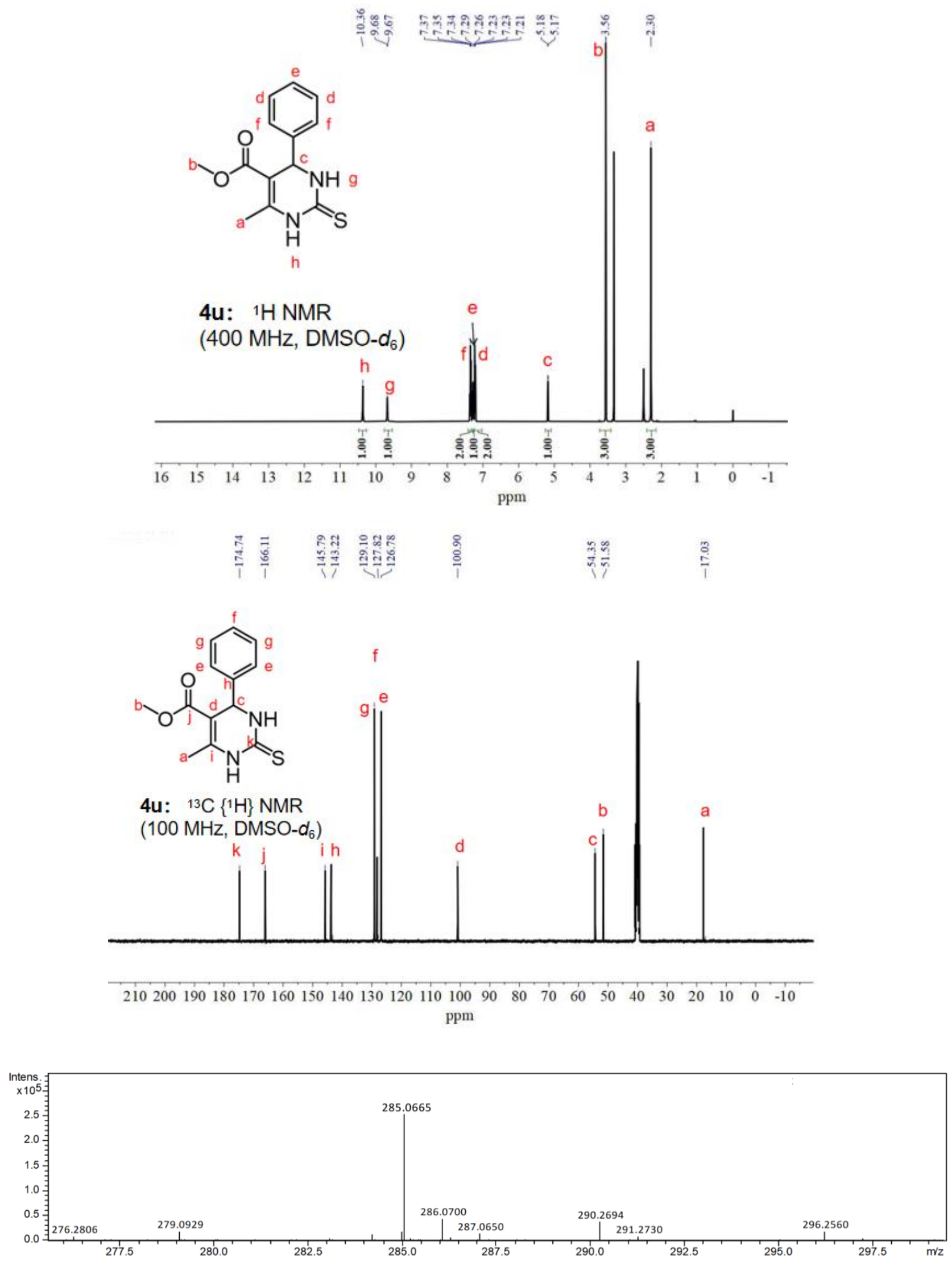

Figure S32. ${ }^{1} \mathrm{H}$ and ${ }^{13} \mathrm{C}$ NMR, and MS spectra for 5-(methoxycarbonyl)-6-methyl-4-phenyl-3,4-dihydropyrimidin2(1H)-thione (Table 1, entry 21, 4u). 


\section{Proposed Mechanism}
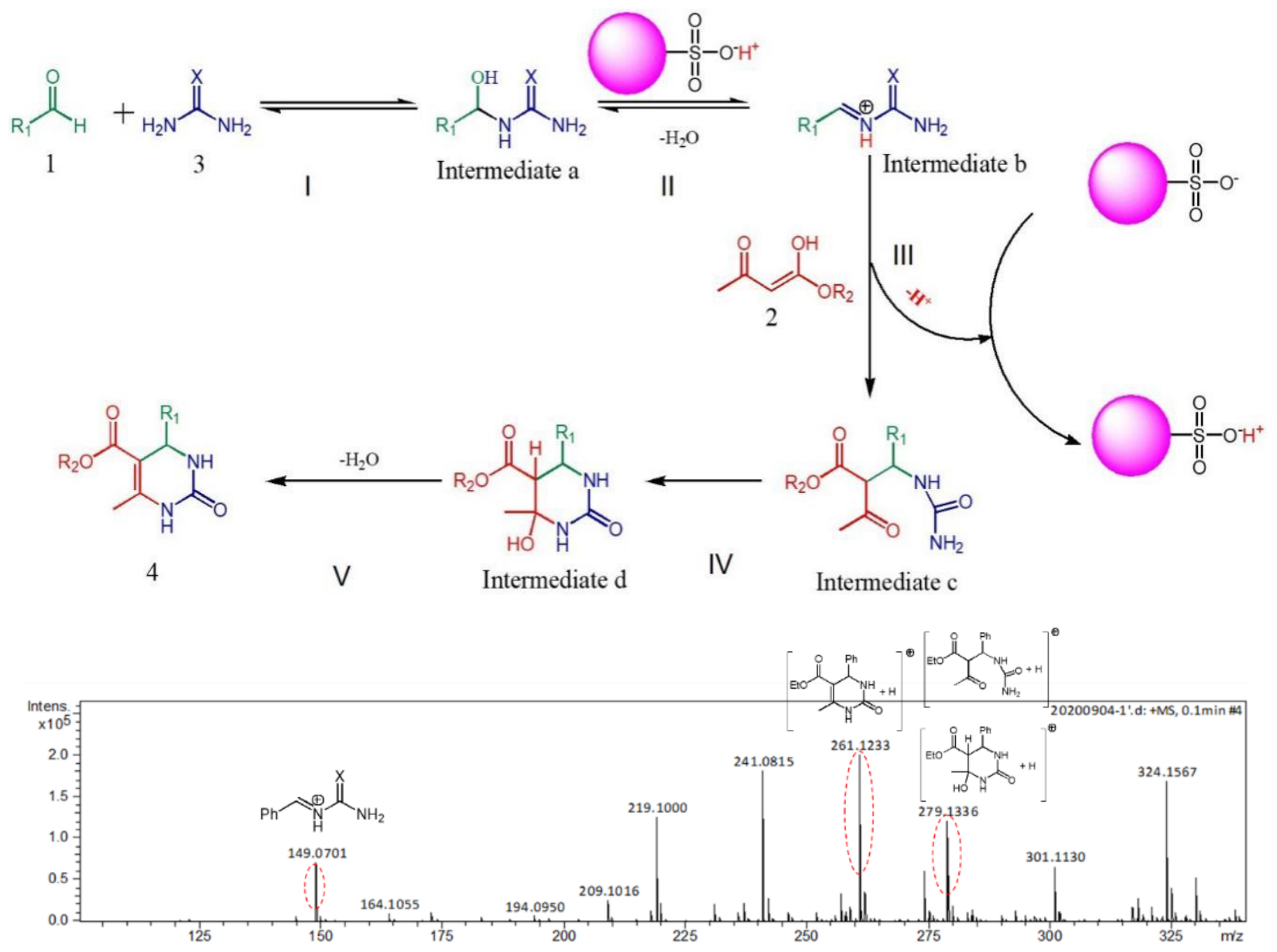

Ph $\overbrace{\mathrm{H}}^{\oplus} \overbrace{\mathrm{NH}_{2}}^{\mathrm{X}}\left[\mathrm{C}_{8} \mathrm{H}_{9} \mathrm{~N}_{2} \mathrm{O}^{+}\right], \mathrm{M}^{+}, \mathrm{m} / \mathrm{z}$, calcd, 149.0709; found, 149.0701

Intermediate b
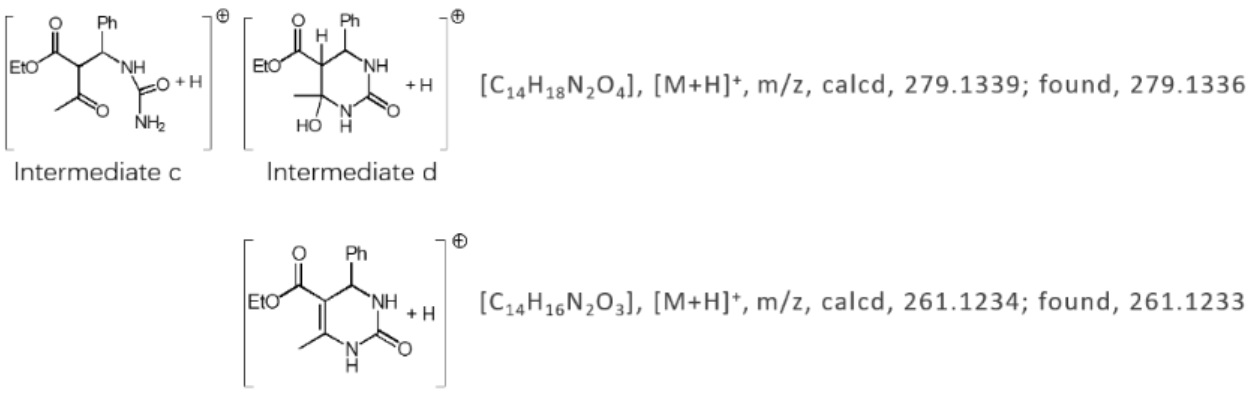

Product 4

Figure S33. Top: proposed mechanism. The first step is believed to be the Mannich-like condensation between the aldehyde and urea. Then, the formed iminium intermediate acts as an electrophile for the nucleophilic addition of the ketoester enol, and the ketone carbonyl of the resulting adduct undergoes condensation with the urea $\mathrm{NH}_{2}$ to give the cyclized product. Bottom: the proposed mechanism was further verified by the MS analysis based on the model Biginelli reaction among benzaldehyde, ethyl acetoacetate and urea. 
6. Scaled-up Model Biginelli Reaction.

a)

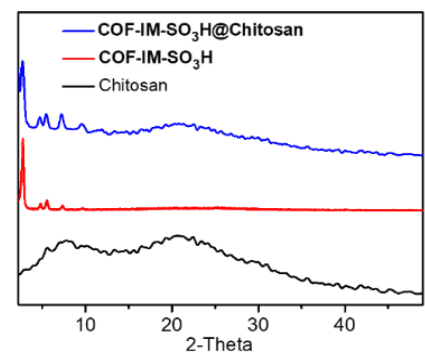

c)

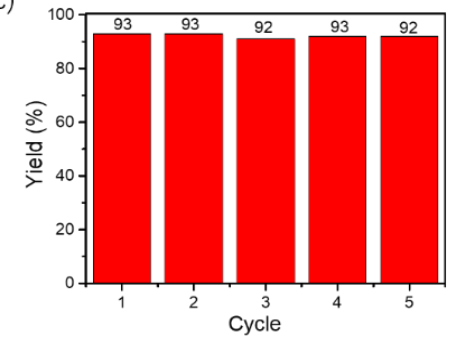

b)

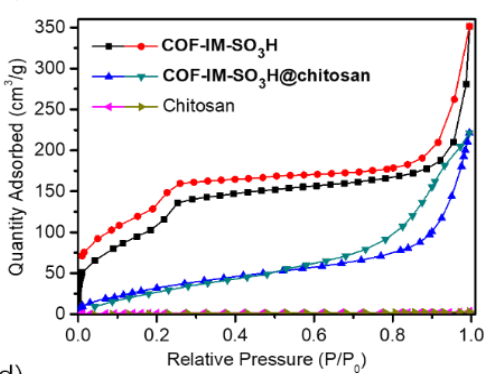

d)

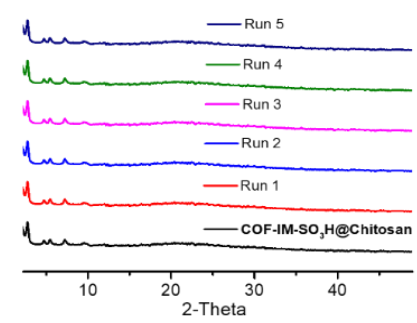

Figure S34. a) $\mathrm{N}_{2}$ adsorption isotherms of COF-IM-SO ${ }_{3} \mathrm{H}, \mathrm{COF}-\mathrm{IM}-\mathrm{SO}_{3} \mathrm{H} @$ chitosan and chitosan. b) PXRD patterns of COF-IM-SO ${ }_{3} \mathrm{H}$, COF-IM-SO ${ }_{3} \mathrm{H} @$ chitosan and chitosan. c) Catalytic cycle. d) PXRD patterns of COF-IM$\mathrm{SO}_{3} \mathrm{H} @$ chitosan and it after five catalytic cycles.

Table S5. List of word abbreviations

\begin{tabular}{|c|c|}
\hline Full name & Abbreviation \\
\hline Smulticomponent Reactions & MCRs \\
\hline Dihydropyrimidine Derivatives & DHPMs \\
\hline Covalent Organic Frameworks & COFs \\
\hline Post-Synthetic Modification & PSM \\
\hline Ionic Liquid & IL \\
\hline Benzaldehyde & $\mathrm{Ba}$ \\
\hline 1-Vinylimidazole & VIM \\
\hline 2,3-Dicyano-5,6-Dichloroben-Quinone & DDQ \\
\hline Powder X-Ray Diffraction & PXRD \\
\hline Brunauer-Emmett-Teller & BET \\
\hline Thermogravimetric Analysis & TGA \\
\hline Energy-Dispersive X-Ray Spectra & EDX-mapping \\
\hline Turnover Number & TON \\
\hline Turnover Frequency & TON \\
\hline Proton Nuclear Magnetic Resonanc & ${ }^{1} \mathrm{H}-\mathrm{NMR}$ \\
\hline Tetramethylsilane & TMS \\
\hline Fourier Transform Infrared Spectrometry & FT-IR \\
\hline High-Resolution Mass Spectrometry & HRMS \\
\hline Solid-State ${ }^{13} \mathrm{C}$ Cross-Polarization Magic Angle Spinning & CP-MAS \\
\hline Scanning Electron Microscopy & SEM \\
\hline Differential Thermal Scanning & DSC \\
\hline
\end{tabular}

